JOURNAL OF APPLIED CIVIL ENGINEERING
AND INFRASTRUCTURE TECHNOLOGY
(JACEIT)
Vol. 1 No. $2(2020) 1-13 \quad$ ISSN Media Elektronik: $2723-5378$

\title{
Analisis Dan Desain Dinamis Pondasi Dangkal Berdasarkan Data CPT
}

\author{
Putera Agung Maha Agung ${ }^{1}$, Josua Sijabat ${ }^{2}$, Nadia Shofi Khairunnisa ${ }^{3}$ \\ ${ }^{1}$ Jurusan Teknik Sipil, Geoteknik, Politeknik Negeri Jakarta \\ ${ }^{2}$ Quality Control, Proyek Hotel Bandara Terminal 3-Soekarno Hatta, PT. Hutama Karya \\ ${ }^{3}$ Alumnus, Jurusan Teknik Sipil, Program Konstruksi Sipil, Politeknik Negeri Jakarta \\ ${ }^{1}$ putera.agungmagung@sipil.pnj.ac.id*
}

\begin{abstract}
A generator set used at the building has to consider some environmental factors so that it would not affect the building structure system and not cause some noises as long as operation time. In order to avoid these disturbances, all foundation systems are not only analyzed and designed in the static calculation but also they must consider some impact factors due to dynamic loading. This study's purpose is to determine the dimensions of shallow foundation and specifications of rubber as a vibration damper in accordance with applicable regulations. The static calculation analyzes the immediate and consolidation settlements, and bearing capacity that occurred at the soil foundation using the Schmertmann method. The dynamic analysis calculates some magnitudes of frequency and or amplitude, and also attenuation of single and couple mode vibration in vertical, horizontal, longitudinal displacement directions, then also rocking, yawing, and pitching turning moment directions using the Lumped Parameter method from some references. Analysis and design obtained the dimensions of $3.7 \times 1.7 \times 0.7 \mathrm{~m}$ for shallow foundation system and allowable bearing capacity (qall) indicated equals $4.10 \mathrm{~kg} / \mathrm{cm}^{2}$ based on static condition, and $6.20 \mathrm{~kg} / \mathrm{cm}^{2}$ according to static and dynamic conditions, respectively. Then, some assessments in static and dynamic calculations were also found the total settlement $(D)=0.49 \mathrm{~mm}$, amplitude $\left(A_{z}\right)=6.6 \times 10^{-6} \mathrm{~m},\left(A_{x}\right)=3.2 \times 10^{-6} \mathrm{~m}$, and $\left(A_{f}\right)=1.7 \times 10^{-6}$ rad. Generally, the resulting parameters from those analyses and design have fulfilled the existing standard and local government regulations.
\end{abstract}

Keywords: shallow foundation, settlement, bearing capacity, frequency/amplitude, attenuation.

\begin{abstract}
Abstrak
Generator set yang digunakan pada gedung harus memperhatikan beberapa faktor lingkungan, sedemikian sehingga tidak mempengaruhi sistem struktur bangunan dan tidak menimbulkan kebisingan-kebisingan pada saat atau waktu operasi. Untuk menghindari beberapa gangguan tersebut, seluruh sistem pondasi tidak hanya dianalisis dan didesain dalam kondisi statis saja, akan tetapi juga harus mempertimbangkan beberapa faktor dampak akibat beban dinamis. Tujuan studi ini adalah menentukan dimensi-dimensi pondasi dangkal dan spesifikasi karet sebagai suatu peredam getaran sesuai dengan peraturan yang berlaku. Dalam studi ini, perhitungan statis menganalisis penurunan segera dan konsolidasi, serta daya dukung tanah yang terjadi pada lapisan tanah pondasi dengan menggunakan metode Schmertmann. Analisis dinamis menghitung besaran frekuensi dan amplitudo, dan juga atenuasi vibrasi tunggal dan gabungan dalam arah pergerakan vertikal, horizontal, dan longitudinal; kemudian juga akibat putaran momen dari pergoyangan rocking, yawing, dan pitching dengan metode Lumped Parameter dari beberapa literatur. Analisis dan desain telah menghasilkan dimensi 3,7 $* 1,7 * 0,7 \mathrm{~m}$ untuk sistem pondasi dangkal dan daya dukung ijin $\left(\mathrm{q}_{\text {all }}\right)$ menunjukkan $=4,10 \mathrm{~kg} / \mathrm{cm}^{2}$ berdasarkan kondisi statis dan $6,20 \mathrm{~kg} / \mathrm{cm}^{2}$ berdasarkan kondisi statis dan dinamis, secara berurutan. Kemudian, beberapa perkiraan di dalam perhitungan kondisi statis dan dinamis juga mendapatkan penurunan total $(\Delta)=0,49 \mathrm{~mm}$, amplitudo $\left(\mathrm{A}_{\mathrm{z}}\right)=6,6 \times 10^{-6} \mathrm{~m},\left(\mathrm{~A}_{\mathrm{x}}\right)=3,2 \times 10^{-6} \mathrm{~m},\left(\mathrm{~A}_{\phi}\right)=1,7 \times 10^{-6} \mathrm{rad}$. Secara umum, parameter-parameter yang dihasilkan dari analisis dan desain tersebut telah memenuhi peraturan-peraturan standar dan pemerintah setempat yang ada.
\end{abstract}

Kata kunci: pondasi dangkal, penurunan, daya dukung, frekuensi/amplitudo, atenuasi.

Diterima Redaksi : 08-11-2020 | Selesai Revisi : 18-11-2020 | Diterbitkan Online : 04-12-2020

\section{Pendahuluan}

Pondasi merupakan suatu elemen struktur yang berfungsi untuk meneruskan beban dari struktur atas ke tanah dasar pondasi. Umumnya, bangunan-bangunan gedung menggunakan daya listrik yang besar untuk memfasilitasi/mendukung sistem listrik atau elektronik, sehingga membutuhkan daya listrik yang besar. Untuk mendukung kebutuhan tersebut biasanya suatu bangunan menggunakan Genset (Generating-Set). Selain itu, genset berfungsi juga sebagai cadangan daya listrik saat terjadi pemadaman atau pemutusan daya listrik dari PLN (sumber tenaga listrik pemerintah). 
Contoh beberapa bangunan yang menggunakan genset sebagai daya listrik tambahan dan atau cadangan untuk memfasilitasi sistem elektronik yang besar adalah: gedung mall, rumah sakit, workshop dan lain-lain.

Salah satu tipe sistem struktur bawah untuk genset adalah pondasi dangkal untuk perletakan atau dudukan guna menopang genset. Dalam analisis dan desain harus dihitung dari 2 (dua) aspek pembebanan, yaitu: akibat beban statis akibat berat sendiri dan beban dinamis akibat getaran (vibrasi). Dalam studi ini, analisis secara statis tidak dibahas secara detail, dan lebih menekankan kepada analisis perhitungan dinamis.

Dalam studi ini, perhitungan statis menganalisis penurunan total dan daya dukung tanah lapisan tanah pondasi dengan menggunakan metode Schmertmann [5]. Analisis dinamis menghitung besaran frekuensi dan amplitudo, dan juga atenuasi vibrasi tunggal dan gabungan arah vertikal, horizontal, logitudinal, rocking, yawing, dan pitching dengan metode Lumped Parameter berdasarkan literatur yang ada $[13,15,27]$.

Pondasi dangkal yang dianalisis dan direncanakan adalah untuk memikul beban mesin Genset sebagaimana pilihan spesifikasi yang diperlihatkan Gambar 1. Mesin terdiri dari 2 (dua) tipe yang akan digunakan untuk mendukung daya listrik bangunan yang ditinjau, yaitu: tipe skid mounted generator (SMG) dan tipe sound attenuated generator (SAG).

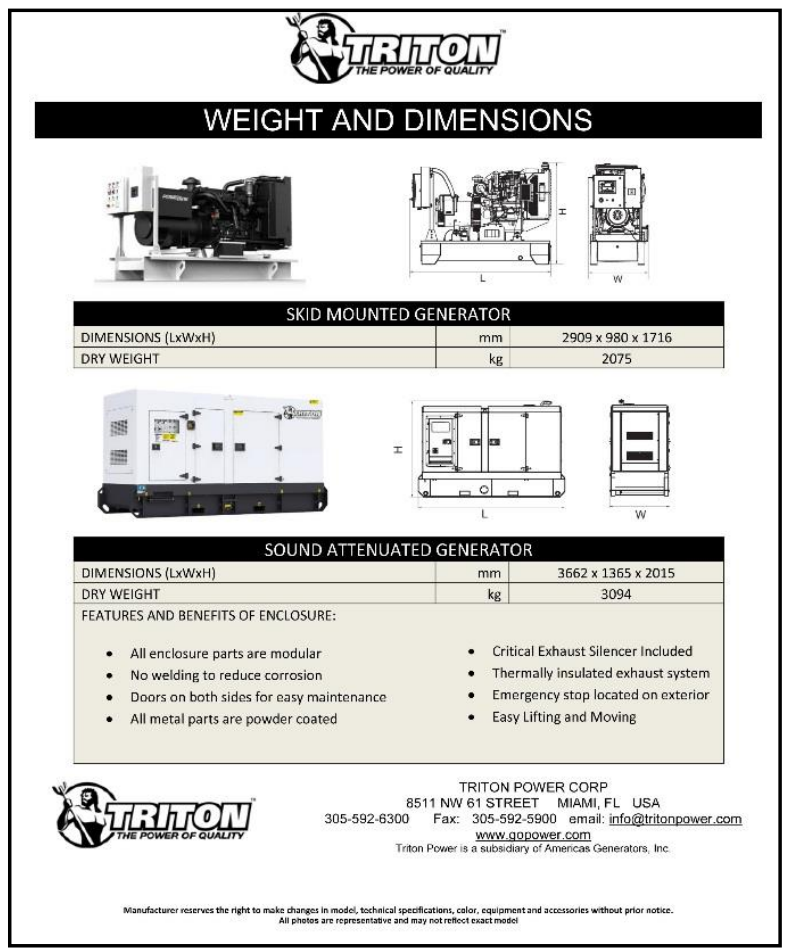

Gambar 1. Pemilihan spesifikasi mesin Genset (USA product) [26]

\section{Metode Penelitian}

Bagan alir studi dapat dijelaskan sebagaimana diperlihatkan dalam Gambar 2. Data tanah yang digunakan adalah hanya data Sondir atau Cone Penetration Test (CPT). Dengan demikian, beberapa data desain yang diperlukan diperoleh dengan menggunakan metode korelasi antar parameter. Data tanah diperlihatkan dalam Gambar 3 dan selanjutnya, lokasi studi diperlihatkan dalam Gambar 4.

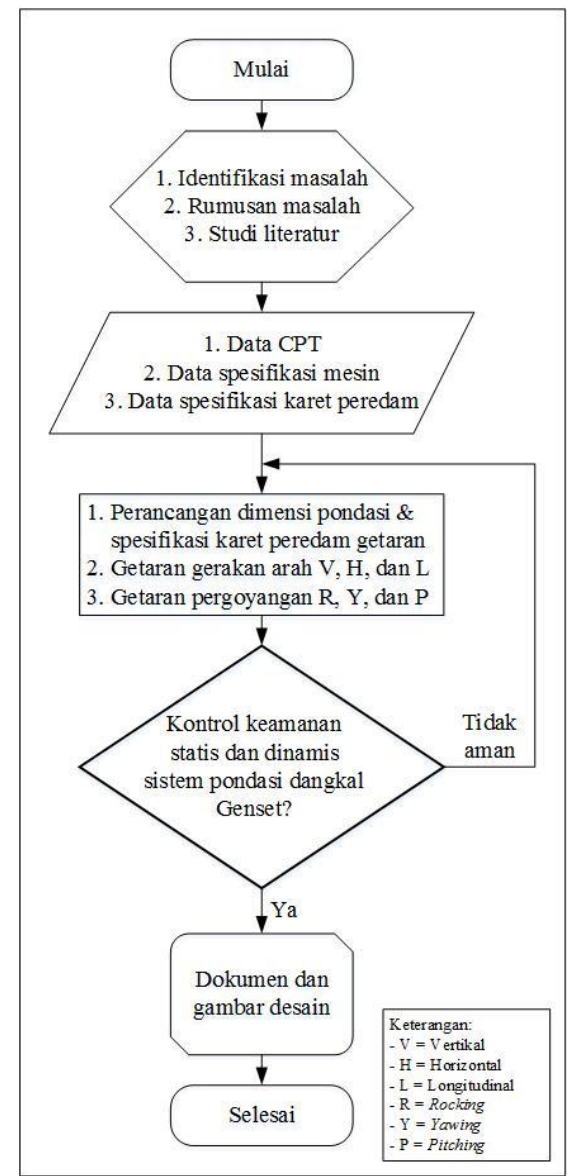

Gambar 2. Bagan alir studi desain pondasi dangkal untuk Genset

\subsection{Interpretasi lapisan tanah di lokasi studi}

Salah satu kelebihan uji lapangan Sondir atau CPT adalah kemampuannya menginterpretasikan lapisan tanah secara kontinu dengan kesalahan minimum. Dalam Gambar 2, diperlihatkan interpretasi lapisan tanah berdasarkan data sondir/CPT menurut referensi $[18,20,21,23]$. Interpretasi lapisan-lapisan tanah dalam di dalam studi ini menggunakan Gambar 5, 6 dan 7. Semua lapisan tanah ditentukan berdasarkan data Sondir yang diplot pada gambar-gambar tersebut.

\subsection{Analisis statis}

2.2.1 Analisis penurunan segera dan konsolidasi

Penurunan akibat berat/beban sendiri dalam sistem pondasi terbagi menjadi 2 (dua), yaitu penurunan segera dan juga penurunan akibat konsolidasi. 
Penurunan segera adalah penurunan yang terjadi secara langsung setelah lapisan tanah dibebani. Menurut Janbu, Bjerrum dan Kjaernsli [9, 11], penurunan segera dapat dirumuskan sebagai berikut:

$\mathrm{S}_{\mathrm{i}}=\mu_{0} \cdot \mu_{1} \cdot \frac{\mathrm{q} \cdot \mathrm{B}}{\mathrm{E}_{\mathrm{s}}}$

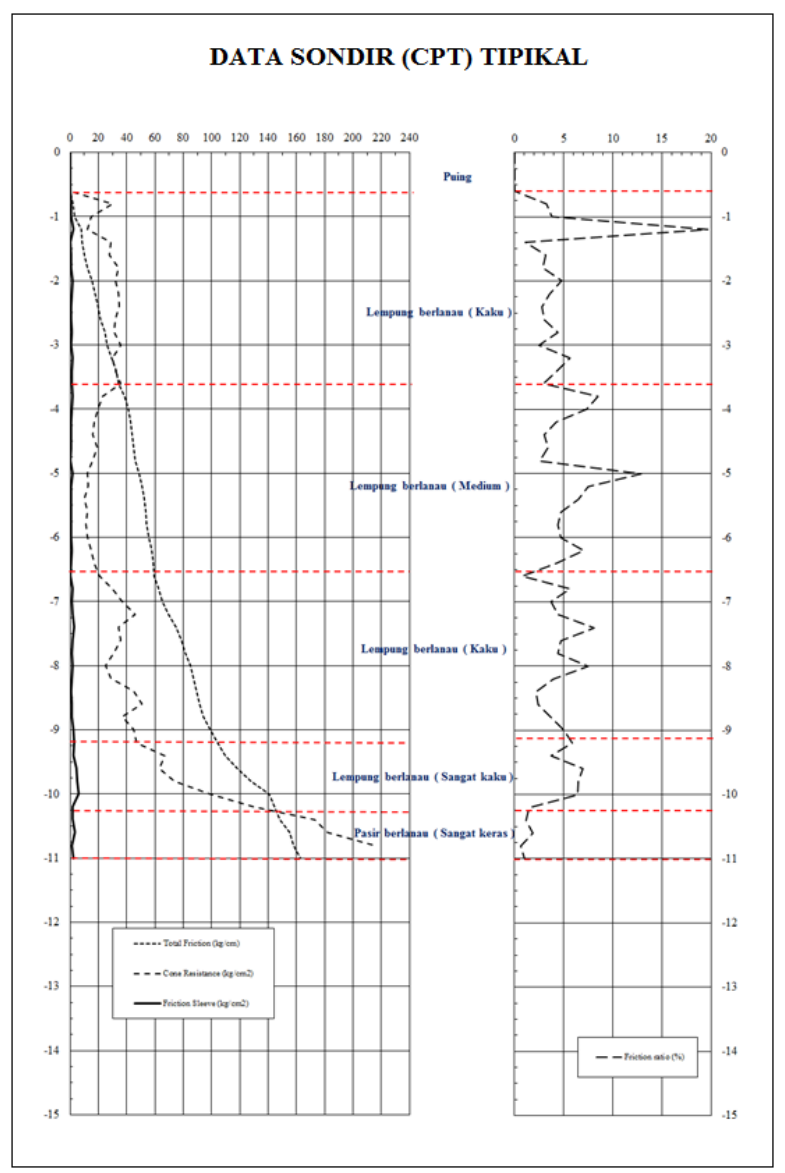

Gambar 3. Data hasil penyelidikan tanah (Sondir/CPT)

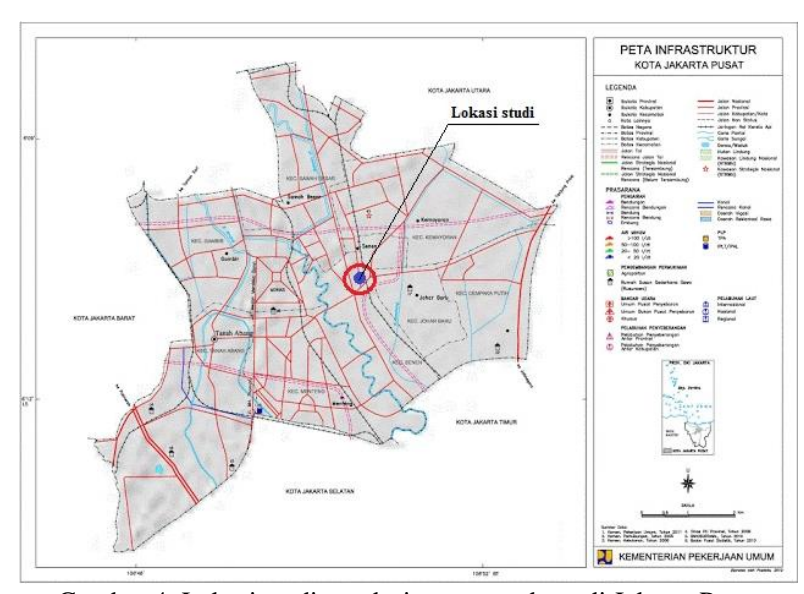

Gambar 4. Lokasi studi pondasi genset gedung di Jakarta Pusat

dengan: $\mathrm{S}_{\mathrm{i}}=$ penurunan segera; $\mathrm{B}=$ lebar pondasi; $\mathrm{E}_{\mathrm{s}}=$ modulus elastisitas (Tabel 1); $\mu_{0}=$ factor koreksi (Gambar 8); $\mu_{1}=$ faktor koreksi (Gambar 9); q = tekanan tanah netto pada pondasi dangkal.

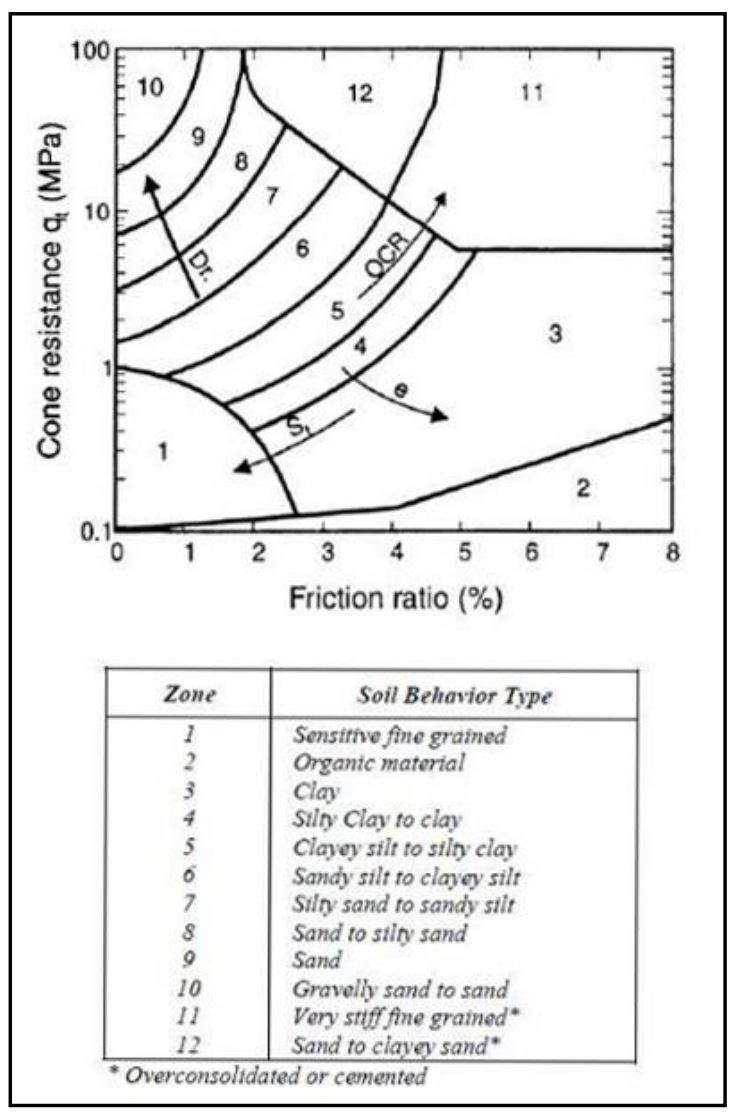

Gambar 5. Lapisan tanah Sondir/CPT berdasarkan $\mathrm{q}_{\mathrm{t}}$ dan $\mathrm{R}_{\mathrm{f}}[18,20]$

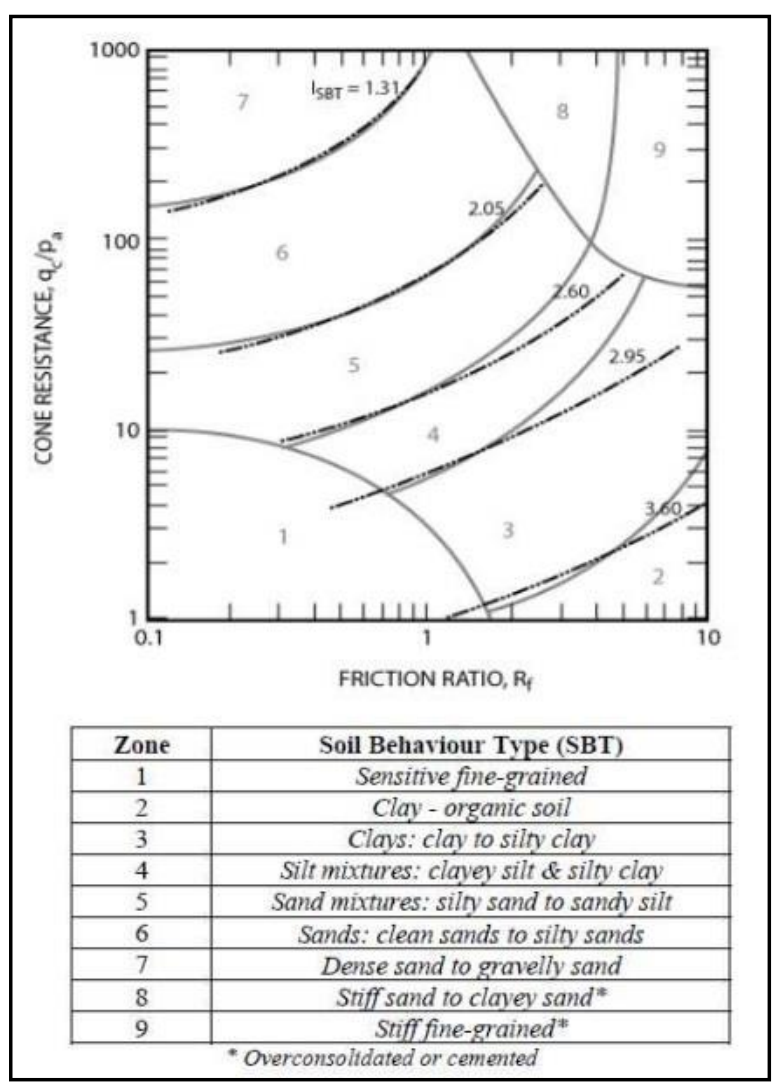

Gambar 6. Lapisan tanah Sondir atau CPT berdasarkan $\mathrm{q}_{\mathrm{c}} / \mathrm{P}_{\mathrm{a}}$ dan $\mathrm{R}_{\mathrm{f}}$ [21] 


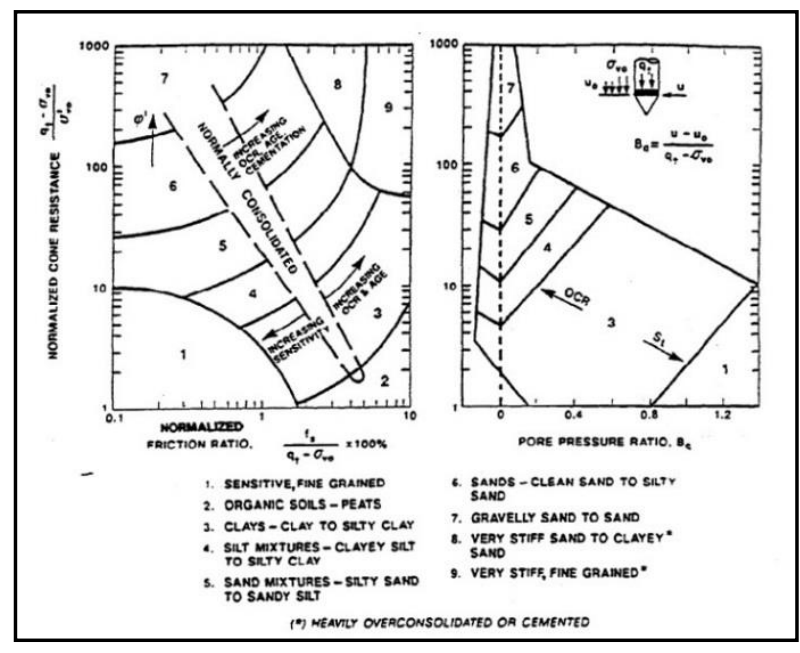

Gambar 7. Lapisan tanah Sondir atau CPT berdasarkan data yang dinormalisasikan [23]

Tabel 1. Modulus elastisitas tanah $\left(\mathrm{E}_{\mathrm{s}}\right)[6,9,17]$

\begin{tabular}{|c|c|}
\hline Jenis tanah & Es $\left(\mathbf{k N} / \mathbf{m}^{\mathbf{2}}\right)$ \\
\hline \multicolumn{2}{|c|}{ Lempung } \\
\hline Sangat lunak & $300-3000$ \\
\hline Lunak & $2000-4000$ \\
\hline Sedang & $4500-9000$ \\
\hline Keras & $3000-20000$ \\
\hline Berpasir & $5000-42500$ \\
\hline \multicolumn{2}{|c|}{ Pasir } \\
\hline Berlanau & $10000-25000$ \\
\hline Tidak padat & $50000-100000$ \\
\hline Padat & $8000-20000$ \\
\hline \multicolumn{2}{|c|}{ Pasir dan kerikil } \\
\hline Padat & $8000-200000$ \\
\hline Tidak padat & $50000-140000$ \\
\hline Lanau & $2000-20000$ \\
\hline Loess & $15000-60000$ \\
\hline Cadas & $140000-1400000$ \\
\hline
\end{tabular}

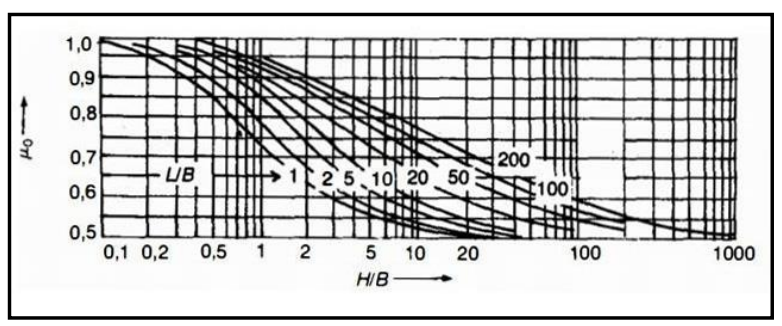

Gambar 8. Grafik koefisien geometris pondasi $\mu_{0}[6,9]$

Penurunan konsolidasi terjadi akibat keluar air tanah melalui pori-pori tanah yang mengakibatkan penurunan dan perubahan angka pori. Penurunan konsolidasi terbagi menjadi dua, yaitu penurunan konsolidasi primer dan sekunder. Penurunan konsolidasi primer terbagi menjadi dua, yaitu konsolidasi normal (normally consolidated) dan terkonsolidasi berlebih (overconsolidated).

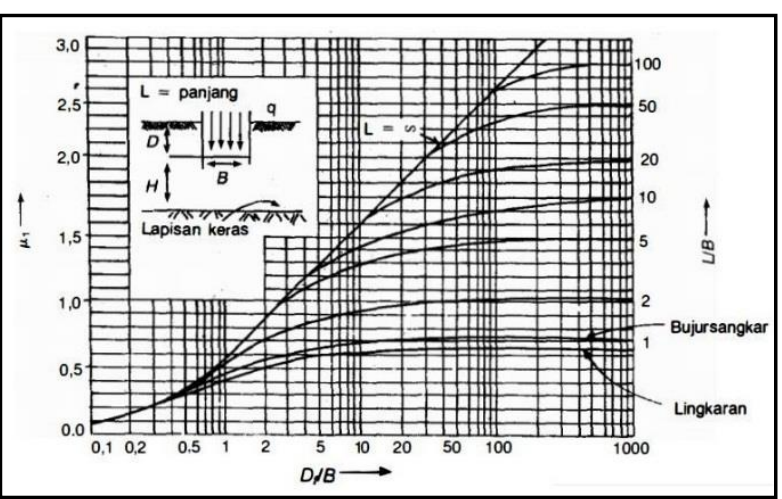

Gambar 9. Grafik koefisien geometris pondasi $\mu_{1}[6,9]$

Beberapa data tanah, ada yang perlu di korelasi atau dicari pendekatannya dengan pendeketan-pendekatan yang ada. Terzaghi menyarankan beberapa data tanah sebagaimana diperlihatkan dalam Tabel 2. Pendekatan terhadap nilai indeks kompresi $\left(\mathrm{C}_{\mathrm{c}}\right)$ menggunakan Tabel 3. Untuk menghitung besarnya penurunan konsolidasi normal bisa digunakan rumus [3]:

$\mathrm{S}_{\mathrm{c}}=\frac{\mathrm{C}_{\mathrm{c}} \cdot \mathrm{H}}{1+\mathrm{e}_{0}} \log \left(\frac{\mathrm{P}_{\mathrm{o}}+\Delta \mathrm{P}}{\mathrm{P}_{\mathrm{o}}}\right)$

dengan: $S_{c}=$ penurunan konsolidasi; $C_{c}=$ nilai index kompresi pendekatan; $\mathrm{e}_{0} \quad=$ angka pori inisial $/$ awal; $\mathrm{P}_{\mathrm{o}}$ $=$ tekanan tanah (overburden pressure); $\Delta \mathrm{P}=$ pertambahan akibat beban luar dengan teori $2: 1$.

Penurunan terkonsolidasi berlebih ditinjau berdasarkan 2 (dua) kondisi, yaitu:

1. $\mathrm{P}_{0}+\Delta \mathrm{P} \leq \mathrm{P}_{\mathrm{c}}$

$$
\mathrm{S}_{\mathrm{c}}=\frac{\mathrm{C}_{\mathrm{s}} \cdot \mathrm{H}}{1+\mathrm{e}_{0}} \log \left(\frac{\mathrm{P}_{\mathrm{o}}+\Delta \mathrm{P}}{\mathrm{P}_{\mathrm{o}}}\right)
$$

2. $\mathrm{P}_{0}<\mathrm{P}_{\mathrm{c}}<\mathrm{P}_{0}+\Delta \mathrm{P}$

$$
S_{c}=\frac{C_{s} \cdot H}{1+e_{0}} \log \left(\frac{P_{o}}{P_{o}}\right)+\frac{C_{c} \cdot H}{1+e_{0}} \log \left(\frac{P_{o}+\Delta P}{P_{o}}\right)
$$

dengan: $\mathrm{C}_{\mathrm{s}}=$ indeks pemuaian (swelling index); $\mathrm{P}_{\mathrm{c}}=$ tegangan pra-konsolidasi (pre-consolidation pressure).

Penurunan pondasi akibat beban statis tidak boleh sangat ekstrim, dimana dapat menimbulkan retak atau kerusakan/cacat pada sistem pondasi. Adapun beberapa kriteria izin dalam batas penurunan seperti yang diusulkan oleh Skempton dan Mac Donald [19]. Untuk daerah studi ini, penurunan pondasi dangkal tidak boleh melebihi $0,05 \mathrm{~cm}(0,5 \mathrm{~mm})$ [22], terlihat dalam Tabel 4.

2.2.2 Daya dukung tanah metode Schmertmann [5, 24] Daya dukung akibat berat/beban sendiri fondasi dangkal dikorelasikan dengan tahanan ujung konus $\mathrm{q}_{\mathrm{c}}$ dengan $\mathrm{D} / \mathrm{B}<1,50$ [22] adalah:

1. Daya dukung batas untuk tanah non-kohesif:

a. Untuk telapak lajur:

$$
\mathrm{q}_{\text {ult }}=28-0,0052\left(300-\mathrm{q}_{\mathrm{c}}\right) \cdot 1,50
$$

b. Untuk telapak persegi:

$$
\mathrm{q}_{\text {ult }}=48-0,0090\left(300-\mathrm{q}_{\mathrm{c}}\right) \cdot 1,50
$$


Tabel 2. Pendekatan nilai $\mathrm{n}, \mathrm{e}, \mathrm{w}, \gamma_{\mathrm{d}}$ dan $\gamma_{\mathrm{t}}$ terhadap data Sondir [6]

\begin{tabular}{|l|c|c|c|c|c|}
\hline \multirow{2}{*}{ Jenis tanah } & $\mathbf{n}$ & \multirow{2}{*}{$\mathbf{w}$} & $\mathbf{w}$ & $\boldsymbol{\gamma}_{\mathbf{d}}$ & $\gamma_{\mathbf{t}}$ \\
\cline { 2 - 3 } & $\mathbf{( \% )}$ & & $\mathbf{( \% )}$ & $\left(\mathbf{k N} / \mathbf{m}^{3}\right)$ & $\mathbf{( k N / \mathbf { m } ^ { 3 } )}$ \\
\hline $\begin{array}{l}\text { Pasir seragam, } \\
\text { tidak padat }\end{array}$ & 46 & 0.85 & 32 & 14.3 & 18.9 \\
\hline $\begin{array}{l}\text { Pasir seragam, } \\
\text { padat }\end{array}$ & 34 & 0.51 & 19 & 17.5 & 20.9 \\
\hline $\begin{array}{l}\text { Pasir berbutir } \\
\text { campuran, tidak } \\
\text { padat }\end{array}$ & 40 & 0.67 & 25 & 15.9 & 19.9 \\
\hline $\begin{array}{l}\text { Pasir berbutir } \\
\text { campuran, padat }\end{array}$ & 30 & 0.43 & 16 & 18.6 & 21.6 \\
\hline $\begin{array}{l}\text { Lempung lunak } \\
\text { sedikit organik }\end{array}$ & 66 & 1.9 & 70 & - & 15.8 \\
\hline $\begin{array}{l}\text { Lempung lunak } \\
\text { sangat organik }\end{array}$ & 75 & 3 & 110 & - & 14.3 \\
\hline
\end{tabular}

Tabel 3. Persamaan empiris untuk $\mathrm{C}_{\mathrm{c}}[6]$

\begin{tabular}{|l|l|l|}
\hline \multicolumn{1}{|c|}{ Pedoman } & \multicolumn{1}{c|}{ Acuan } & \multicolumn{1}{c|}{ Jenis/model tanah } \\
\hline $\mathrm{C}_{\mathrm{c}}=0.007(\mathrm{LL}-0.7)$ & Skempton & Lempung yang terbentuk kembali (remolded $)$ \\
\hline $\mathrm{C}_{\mathrm{c}}=0.01\left(\mathrm{~W}_{\mathrm{n}}\right)$ & & Lempung Chicago \\
\hline $\mathrm{C}_{\mathrm{c}}=1.15\left(\mathrm{e}_{\mathrm{o}}-0.27\right)$ & Nishida & Semua lempung \\
\hline $\mathrm{C}_{\mathrm{c}}=0.30\left(\mathrm{e}_{\mathrm{o}}-0.27\right)$ & Hough & Tanah kohesi anorganik: lanau, lempung berlanau lempung \\
\hline $\mathrm{C}_{\mathrm{c}}=0.0015 \mathrm{WW}$ & & Tanah organik, gambut, lanau erganik dan dempung. \\
\hline $\mathrm{C}_{\mathrm{c}}=0.0046(\mathrm{LL}-9)$ & & Lempung Brazilia \\
\hline $\mathrm{C}_{\mathrm{c}}=0.75\left(\mathrm{e}_{\mathrm{o}}-15\right)$ & & Tanah dengan plastisitas rendah \\
\hline $\mathrm{C}_{\mathrm{c}}=0.208 \mathrm{e}_{\mathrm{o}}+0.0083$ & & Lempung Chicago \\
\hline $\mathrm{C}_{\mathrm{c}}=0.156 \mathrm{e}_{\mathrm{o}}+0.0107 \mathrm{e}_{\mathrm{o}}$ & & Semua lempung \\
\hline
\end{tabular}

Tabel 4. Batasan penurunan pondasi yang diizinkan [22]

\begin{tabular}{ccc}
\hline No. & Jenis bangunan & $\begin{array}{c}\text { Penurunan } \\
\text { maksimum }(\mathrm{cm})\end{array}$ \\
\hline 1. & Bangunan umum & 2,54 \\
\hline 2. & Bangunan pabrik & 3,81 \\
\hline 3. & Gudang & 5,08 \\
\hline 4. & Pondasi mesin & 0,05 \\
\hline
\end{tabular}

2. Daya dukung batas untuk tanah kohesif:

a. Untuk lajur:

$\mathrm{q}_{\text {ult }}=2+0,28 \mathrm{q}_{\mathrm{c}}$

b. Untuk persegi:

$$
\mathrm{q}_{\text {ult }}=5+0,34 \mathrm{q}_{\mathrm{c}}
$$

dengan: $\mathrm{q}_{\mathrm{ult}}=$ daya dukung ultimit; $\mathrm{q}_{\mathrm{c}}=$ tekanan konus rata-rata mulai $\mathrm{B} / 2$ di atas sampai $1,1 \mathrm{~B}$ di bawah alas telapak pondasi dangkal untuk $\mathrm{D} / \mathrm{B}<1,50$.

\subsection{Analisis dinamis}

\subsubsection{Pemilihan tipe pondasi}

Pondasi mesin merupakan pondasi yang memikul mesin. Pondasi mesin dapat berupa pondasi dangkal dan pondasi dalam. Dalam kasus ini direncanakan pondasi mesin berupa pondasi dangkal. Adapun tipe-tipe pondasi dangkal untuk mesin $[15,16]$, yaitu tipe blok (block type foundation), pondasi kotak (box or cassion type of foundation), dan pondasi dinding (wall type foundation). Dalam perencanaan pondasi mesin akibat beban dinamis oleh adanya getaran mesin digunakan beberapa pertimbangan, yaitu: getaran adalah gerak harmonik sederhana atau peristiwa gejala gerak bolak balik pada suatu sistem; waktu bagi benda untuk melakukan satu osilasi biasa disebut periode (T) dan banyaknya getaran dalam satu detik disebut frekuensi (F); jika frekuensi paksa sama (saat Genset dihidupkan pertama kali) dengan frekuensi alami sistem, sistem akan berosilasi dengan amplitudo yang jauh lebih besar daripada amplitudo gaya paksa, kejadian ini disebut suatu resonansi (R); bila energi mekanik gerak osilasi berkurang terhadap waktu, gerak dikatakan teredam (D); dan struktur pondasi dangkal sangat tergantung oleh momen inersia (I) bentuk struktur atau dinyatakan sebagai suatu angka yang menyatakan kelembaman suatu benda untuk melakukan rotasi. Di dalam studi ini dipilih tipe pondasi dangkal blok, sehingga I bisa diambil dari di dalam Gambar 10.

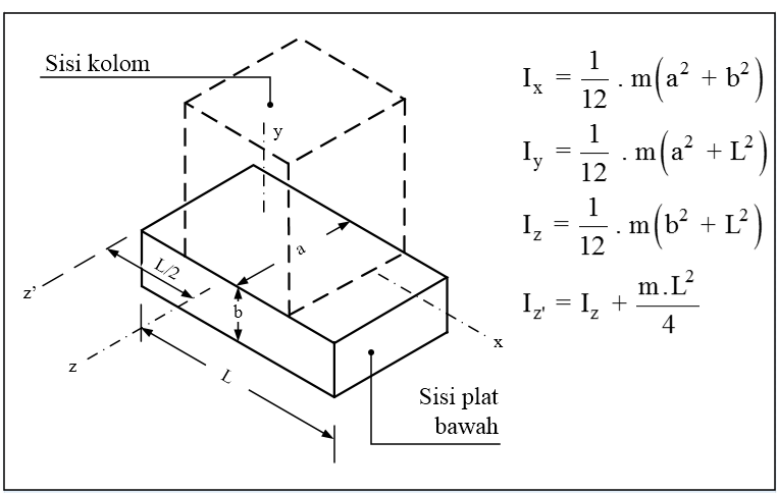

Gambar 10. Tipe blok dan besaran momen inersia (I) $[5,8,15]$

Dalam perencanaan pondasi dangkal untuk mesin Genset terdapat 6 derajat kebebasan (degree of freedom/DOF) [15], yaitu; vertikal, horizontal, rocking, longitudinal, yawing, pitching sebagaimana dalam Gambar 11. Namun, untuk studi ini ditinjau secara keseluruhan sesuai dengan tipe mesin Genset yang diusulkan untuk dipasang dalam gedung (Gambar 1).

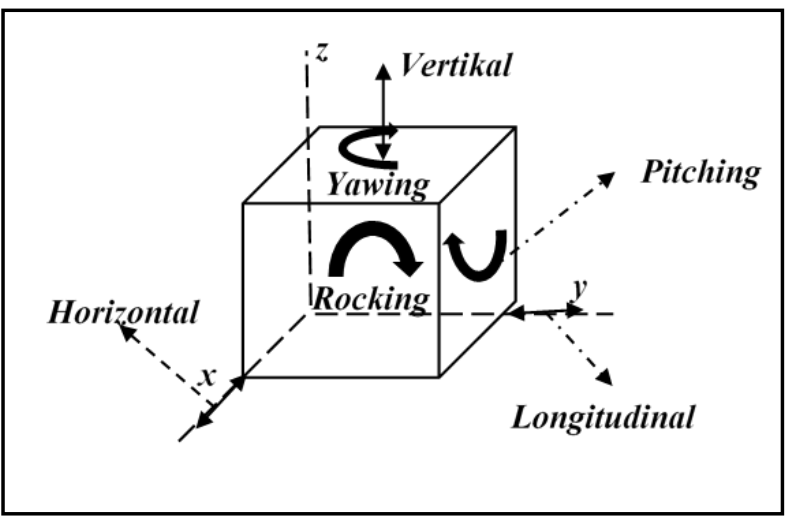

Gambar 11. Derajat kebebasan sistem struktur analisis dinamis [15]

2.2.2 Analisis dinamis dalam arah gerak vertikal

Getaran yang mengakibatkan suatu pondasi bergerak ke atas dan ke bawah searah sumbu $z$. Untuk mengetahui 
getaran vertikal pada pondasi mesin, berikut beberapa hal yang harus diperhitungkan $[13,28]$ :

1. Radius ekivalen $\left(\mathrm{r}_{\mathrm{z}}\right)$ :

$$
\mathrm{r}_{\mathrm{z}}=\sqrt{\mathrm{B} \cdot \mathrm{L} / \pi}
$$

Dengan: $\mathrm{L}=$ lebar pondasi; $\mathrm{B}=$ panjang pondasi.

2. Koefisien kedalaman $\left(\eta_{\mathrm{z}}\right)$ :

$$
\eta_{\mathrm{z}}=1+0,60(1-v)\left(\mathrm{h} / \mathrm{r}_{\mathrm{z}}\right)
$$

Dengan: $v=$ rasio Poisson; $\mathrm{h}=$ kedalaman pondasi

3. Koefisien pegas $\left(\mathrm{k}_{\mathrm{z}}\right)$ :

$$
\mathrm{k}_{\mathrm{z}}=\frac{\mathrm{G}}{1-v} \cdot \beta_{\mathrm{z}} \cdot \sqrt{\mathrm{B} \cdot \mathrm{L}} \cdot \eta_{\mathrm{z}}
$$

Dengan: $G=$ modulus geser tanah $\left(\right.$ Tabel 5); $\beta_{z}=$ faktor geometris letak pondasi (Gambar 12).

Tabel 5. Harga tipikal modulus geser $(\mathrm{G})[1,7,10]$

\begin{tabular}{|lc|}
\hline \multicolumn{1}{|c|}{ Jenis tanah } & $\mathrm{G}\left(\mathrm{kg} / \mathrm{cm}^{2}\right)$ \\
\hline Soft clay & $2100-3500$ \\
\hline Stiff clay & $7000-14000$ \\
\hline Very stiff to hard & $>14000$ \\
\hline Medium dense sand & $3500-10500$ \\
\hline Dense sand & $7000-14000$ \\
\hline Medium dense gravel & $10500-17500$ \\
\hline Dense gravel & $14000-28000$ \\
\hline
\end{tabular}

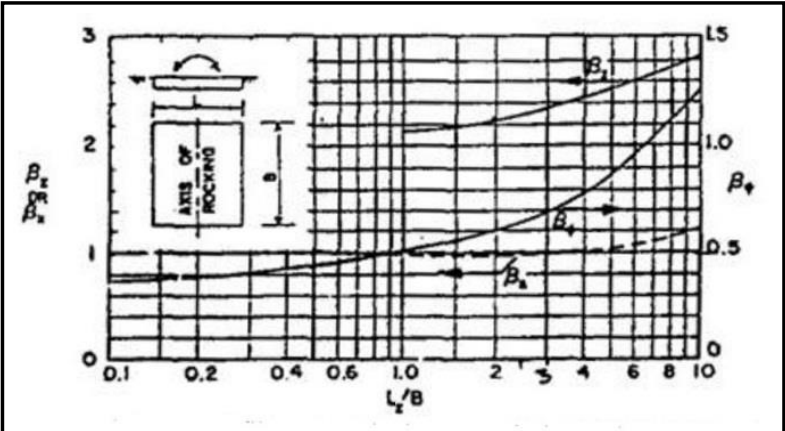

Gambar 12. Grafik geometris dasar pondasi [13, 28]

4. Rasio massa $\left(\mathrm{B}_{\mathrm{z}}\right)$ :

$$
\mathrm{B}_{\mathrm{z}}=\frac{1-v}{4} \cdot \frac{\mathrm{W}}{\gamma \cdot \mathrm{r}_{\mathrm{z}}^{3}}
$$

dengan: $\mathrm{W}=$ berat pondasi dengan mesin; $\gamma=$ berat isi tanah $\left(\mathrm{kg} / \mathrm{m}^{3}\right)$.

5. Rasio redaman sesuai kedalaman pondasi $\left(\alpha_{z}\right)$ :

$$
\alpha_{\mathrm{z}}=\frac{1+1,9(1-v) \frac{\mathrm{h}}{\mathrm{r}_{\mathrm{z}}}}{\sqrt{\eta_{\mathrm{z}}}}
$$

6. Rasio redaman sesuai lebar dan kedalaman $\left(D_{z}\right)$ :

$\mathrm{D}_{\mathrm{z}}=\frac{0,425}{\sqrt{\mathrm{B}_{\mathrm{z}}}} \cdot \alpha_{\mathrm{z}}$

7. Frekuensi natural $\left(f_{\mathrm{nz}}\right)$ :

$\mathrm{f}_{\mathrm{nz}}=\frac{1}{2 \pi} \cdot \sqrt{\frac{\mathrm{k}_{\mathrm{z}}}{\mathrm{m}}}$

dengan: $m=$ massa sistem mesin Genset

8. Frekuensi resonansi $\left(\mathrm{f}_{\mathrm{r}}\right)$ :

$$
f_{r}=f_{n z} \cdot \sqrt{1-2 D_{z}^{2}}
$$

$\mathrm{F}_{0}=\mathrm{m} \cdot \mathrm{e} \cdot \omega^{2}$

Dengan: $\mathrm{e}=$ eksentrisitas dari motor Genset, didapatkan dari perumusan oleh American Petroleum Institute Standard for Centrifugal Compressors (API Standard), yaitu:

$\mathrm{e}(\mathrm{mil})=\alpha \cdot \sqrt{12000 / \omega}<1,0(\mathrm{mil})$

Pada kasus ini mesin Genset dianggap beroperasi pada kecepatan tetap dan juga nilai untuk gaya dinamis vertikal dan horizontal dianggap sama. Diambil nilai e $=1,0 \mathrm{mil}=1,54 \cdot 10^{-5} \mathrm{~m}$.

10. Rasio frekuensi (f):

$$
\mathrm{f}=\frac{\mathrm{f}_{0}}{\mathrm{f}_{\mathrm{r}}}
$$

10. Kecepatan sudut $\left(\omega_{\mathrm{nz}}\right)$ :

$$
\omega_{\mathrm{nz}}=\sqrt{\frac{\mathrm{k}_{\mathrm{z}}}{\mathrm{m}}}
$$

11.Rasio kecepatan sudut $\left(\mathrm{r}_{\mathrm{z}}\right)$ :

$$
\mathrm{r}_{\mathrm{z}}=\frac{\omega}{\omega_{\mathrm{nz}}}
$$

dengan : $\omega=$ kecepatan sudut mesin

12. Amplitudo $\left(\mathrm{A}_{\mathrm{z}}\right)$ :

$$
A_{z}=\frac{F_{0}}{k_{z} \sqrt{\left(1-r_{z}^{2}\right)+\left(2 \cdot D_{z} \cdot r_{z}\right)^{2}}}
$$

2.2.3 Analisis dinamis dalam arah gerak horizontal Getaran horizontal adalah getaran yang mengakibatkan suatu pondasi bergerak arah sumbu x. Untuk mengetahui getaran lateral pada pondasi mesin, berikut hal yang harus diperhitungkan $[4,22]$ :

1. Radius ekivalen $\left(\mathrm{r}_{\mathrm{x}}\right)$ :

$$
r_{\mathrm{x}}=\sqrt{\mathrm{B} \cdot \mathrm{L} / \pi}
$$

2. Koefisien kedalaman $\left(\eta_{\mathrm{x}}\right)$ :

$$
\eta_{\mathrm{x}}=1+0,55(1-v)\left(\mathrm{h} / \mathrm{r}_{\mathrm{x}}\right)
$$

3. Koefisien pegas $\left(\mathrm{k}_{\mathrm{x}}\right)$ :

$$
\mathrm{k}_{\mathrm{x}}=2 \cdot(1+v) \cdot \mathrm{G} \cdot \beta_{\mathrm{x}} \cdot \sqrt{\mathrm{B} \cdot \mathrm{L}} \cdot \eta_{\mathrm{x}}
$$

4. Rasio massa $\left(B_{\mathrm{x}}\right)$ :

$$
\mathrm{B}_{\mathrm{x}}=\frac{7-8 \cdot v}{32(1-v)} \cdot \frac{\mathrm{W}}{\gamma \cdot \mathrm{r}_{\mathrm{x}}{ }^{3}}
$$

5. Rasio redaman sesuai kedalaman pondasi $\left(\alpha_{\mathrm{x}}\right)$ :

$$
\alpha_{\mathrm{x}}=\frac{1+1,9(1-v) \frac{\mathrm{h}}{\mathrm{r}_{\mathrm{x}}}}{\sqrt{\eta_{\mathrm{x}}}}
$$

6. Rasio redaman sesuai lebar dan kedalaman $\left(D_{x}\right)$ :

$$
\mathrm{D}_{\mathrm{x}}=\frac{0,288}{\sqrt{\mathrm{B}_{\mathrm{x}}}} \cdot \alpha_{\mathrm{x}}
$$

7. Frekuensi natural $\left(f_{n x}\right)$ :

$$
f_{n x}=\frac{1}{2 \pi} \cdot \sqrt{\frac{k_{x}}{m}}
$$

8. Frekuensi resonansi $\left(\mathrm{f}_{\mathrm{r}}\right)$ :

$$
\mathrm{f}_{\mathrm{r}}=\mathrm{f}_{\mathrm{nx}} \cdot \sqrt{1-2 \mathrm{D}_{\mathrm{x}}^{2}}
$$

9. Kecepatan sudut $\left(\omega_{\mathrm{nx}}\right)$ :

$$
\omega_{\mathrm{nx}}=\sqrt{\frac{\mathrm{k}_{\mathrm{x}}}{\mathrm{m}}}
$$

10.Rasio kecepatan sudut $\left(\mathrm{r}_{\mathrm{x}}\right)$ :

$$
\mathrm{r}_{\mathrm{x}}=\frac{\omega}{\omega_{\mathrm{nx}}}
$$

9. Gaya dinamis $\left(\mathrm{F}_{\mathrm{o}}\right)$ : 
11.Amplitudo $\left(\mathrm{A}_{\mathrm{x}}\right)$ :

$$
A_{x}=\frac{F_{0}}{k_{x} \sqrt{\left(1-r_{x}^{2}\right)+\left(2 \cdot D_{x} \cdot r_{x}\right)^{2}}}
$$

2.2.4 Analisis dinamis dalam arah goyangan rocking Getaran rocking adalah getaran yang mengakibatkan suatu pondasi berputar terhadap sumbu y. Jika $\frac{\sqrt{f_{n x}^{2}}+\sqrt{f_{0^{2}}}}{f_{n x} \cdot f_{o}} \leq \frac{2}{3 \cdot f}$, maka kopel atau getaran gandeng bisa diabaikan atau dihitung terpisah $[4,22]$. Untuk mengetahui getaran tunggal rocking pada pondasi mesin, berikut hal yang harus diperhitungkan adalah:
1. Radius ekivalen $\left(\mathrm{r}_{\phi}\right)$ :

$$
\mathrm{r}_{\phi}=\sqrt[4]{\mathrm{B} \cdot \mathrm{L}^{3} / 3 \pi}
$$

2. Koefisien kedalaman $\left(\eta_{\phi}\right)$ :

$$
\eta_{\phi}=1+1,2(1-v)(\mathrm{h} / \mathrm{r} \phi)+1+0,2(2-v)(\mathrm{h} / \mathrm{r} \phi)^{2}
$$

3. Koefisien pegas $\left(\mathrm{k}_{\phi}\right)$ :

$$
\mathrm{k}_{\phi}=\frac{\mathrm{G}}{1-v} \cdot \beta_{\phi} \cdot \mathrm{B} \cdot \mathrm{L}^{2} \cdot \eta_{\phi}
$$

4. Momen akibat gaya dinamis pada sumbu y $\left(\mathrm{M}_{\mathrm{y}}\right)$ : $\mathrm{M}_{\mathrm{y}}=\mathrm{F}_{\mathrm{o}}$ (tinggi pondasi + tinggi pusat rotasi mesin titik berat sistem arah vertikal)

5. Rasio massa $\left(\mathrm{B}_{\phi}\right)$ :

$$
\mathrm{B}_{\phi}=\frac{3 \cdot(1-v) \cdot \mathrm{M}_{\mathrm{y}}}{8 \cdot \gamma \cdot \mathrm{r}_{\phi}{ }^{3}}
$$

Dengan: $\mathbf{M}_{\mathrm{y}}=$ momen massa mesin terhadap sumbu y sesuai nilai $\mathrm{I}_{\mathrm{y}}$. $\mathrm{I}_{\mathrm{y}}$ adalah momen inersia berdasarkan bentuk prisma segiempat (rectangular prism) dari tabel [13, 22] merupakan kumulatif sisi/bagian plat bawah dan bagian kolom pondasi dangkal seperti diperlihatkan dalam Gambar 10.

6. Rasio redaman sesuai kedalaman pondasi $\left(\alpha_{\phi}\right)$ :

$$
\alpha_{\phi}=\frac{1+0,7(1-v) \frac{\mathrm{h}}{\mathrm{r}_{\phi}}+1+0,6(2-v)\left(\frac{\mathrm{h}}{\mathrm{r}_{\phi}}\right)^{3}}{\sqrt{\eta_{\phi}}}
$$

7. Rasio redaman sesuai lebar dan kedalaman $\left(D_{\phi}\right)$ :

$$
\mathrm{D}_{\phi}=\frac{0,15 \cdot \alpha_{\phi}}{\left(1+\eta_{\phi} \cdot \beta_{\phi}\right) \sqrt{\eta_{\phi} \cdot \mathrm{B}_{\phi}}} \cdot \alpha_{\phi}
$$

8. Frekuensi natural $\left(\mathrm{f}_{\mathrm{n} \phi}\right)$ :

$$
\mathrm{f}_{\mathrm{n} \phi}=\frac{1}{2 \pi} \cdot \sqrt{\frac{\mathrm{k}_{\phi}}{\mathrm{m}}}
$$

9. Frekuensi resonansi $\left(f_{r}\right)$ :

$$
\mathrm{f}_{\mathrm{r}}=\mathrm{f}_{\mathrm{n} \phi} \cdot \sqrt{1-2 \mathrm{D}_{\phi}^{2}}
$$

10. Kecepatan sudut $\left(\omega_{\mathrm{n} \phi}\right)$ :

$$
\omega_{\mathrm{n} \phi}=\sqrt{\frac{\mathrm{k}_{\phi}}{\mathrm{m}}}
$$

11. Rasio kecepatan sudut $\left(\mathrm{r}_{\phi}\right)$ :

$$
\mathrm{r}_{\phi}=\frac{\omega}{\omega_{\mathrm{n} \phi}}
$$

12. Amplitudo $\left(\mathrm{A}_{\phi}\right)$ :

$$
\mathrm{A}_{\phi}=\frac{\mathrm{M}_{\mathrm{y}}}{\mathrm{k}_{\phi} \sqrt{\left(1-\mathrm{r}_{\phi}^{2}\right)+\left(2 \cdot \mathrm{D}_{\phi}\right)^{2}}}
$$

2.2.5 Analisis dinamis dalam arah gerak longitudinal
Getaran longitudinal adalah getaran yang mengakibatkan suatu pondasi bergerak arah sumbu y. Getaran longitudinal pada pondasi mesin dihitung [7]:

1. Radius ekivalen $\left(\mathrm{r}_{\mathrm{y}}\right)$ :

$$
\mathrm{r}_{\mathrm{y}}=\sqrt{\mathrm{B} \cdot \mathrm{L} / \pi}
$$

2. Koefisien pegas $\left(\mathrm{k}_{\mathrm{y}}\right)$ :

$$
\mathrm{k}_{\mathrm{y}}=\frac{32(1-v) \mathrm{G} \cdot \mathrm{r}_{\mathrm{y}}}{7-8 v}
$$

3. Rasio massa $\left(B_{y}\right)$ :

$$
\mathrm{B}_{\mathrm{y}}=\frac{7-8 v}{32(1-v)} \cdot \frac{\mathrm{m}}{\gamma \cdot \mathrm{r}_{\mathrm{y}}{ }^{3}}
$$

4. Rasio redaman sesuai lebar pondasi $\left(D_{y}\right)$ :

$$
\mathrm{D}_{\mathrm{y}}=\frac{0,2875}{\sqrt{\mathrm{B}_{\mathrm{y}}}}
$$

5. Frekuensi natural $\left(f_{n y}\right)$ :

$$
f_{n y}=\frac{1}{2 \pi} \cdot \sqrt{\frac{k_{y}}{m}}
$$

6. Frekuensi resonansi $\left(f_{r}\right)$ :

$$
\mathrm{f}_{\mathrm{r}}=\mathrm{f}_{\mathrm{ny}} \cdot \sqrt{1-2 \mathrm{D}_{\mathrm{y}}{ }^{2}}
$$

7. Kecepatan sudut $\left(\omega_{\mathrm{ny}}\right)$ :

$$
\omega_{\text {ny }}=\sqrt{\frac{\mathrm{k}_{\mathrm{y}}}{\mathrm{m}}}
$$

8. Rasio kecepatan sudut $\left(\mathrm{r}_{\mathrm{y}}\right)$ :

$$
r_{\mathrm{y}}=\frac{\omega}{\omega_{\mathrm{ny}}}
$$

9. Amplitudo $\left(\mathrm{A}_{\mathrm{y}}\right)$ :

$$
A_{y}=\frac{F_{0}}{k_{y} \sqrt{\left(1-r_{y}^{2}\right)^{2}+\left(2 \cdot D_{y} \cdot r_{y}\right)^{2}}}
$$

2.2.6 Analisis dinamis dalam arah goyangan yawing

1. Radius ekivalen $\left(\mathrm{r}_{\psi}\right)$ :

$$
r_{\psi}=\sqrt{\frac{B \cdot L\left(B^{2}+L^{2}\right)}{6 . \pi}}
$$

2. Koefisien pegas $\left(\mathrm{k}_{\psi}\right)$ :

$$
\mathrm{k}_{\psi}=\frac{16 \cdot \mathrm{G} \cdot \mathrm{r}_{\psi}{ }^{2}}{3}
$$

3. Rasio massa $\left(\mathrm{B}_{\psi}\right)$ :

$$
\mathrm{B}_{\psi}=\frac{\mathrm{M}_{\mathbf{z}}}{\gamma \cdot \mathrm{r}_{\psi}{ }^{5}}
$$

Dengan: $\mathrm{M}_{\mathrm{Z}}=$ momen massa mesin terhadap sumbu $\mathrm{z}$ sesuai nilai $\mathrm{I}_{\mathrm{z}}$. $\mathrm{I}_{\mathrm{z}}$ diambil berdasarkan bentuk prisma segiempat dari Gambar 10 [13, 22].

4. Rasio redaman sesuai lebar pondasi $\left(D_{\psi}\right)$ :

$$
\mathrm{D}_{\psi}=\frac{0,50}{1+2 \cdot \mathrm{B}_{\psi}}
$$

5. Frekuensi natural $\left(f_{n \psi}\right)$ :

$$
\mathrm{f}_{\mathrm{n} \psi}=\frac{1}{2 \pi} \cdot \sqrt{\frac{\mathrm{k}_{\psi}}{\mathrm{m}}}
$$

9. Frekuensi resonansi $\left(f_{r}\right)$ :

$$
\mathrm{f}_{\mathrm{r}}=\mathrm{f}_{\mathrm{n} \psi} \cdot \sqrt{1-2 \mathrm{D}_{\psi}^{2}}
$$

6. Kecepatan sudut $\left(\omega_{\mathrm{n} \psi}\right)$ :

$$
\omega_{\mathrm{n} \psi}=\sqrt{\frac{\mathrm{k}_{\psi}}{\mathrm{m}}}
$$

7. Kecepatan sudut terendam $\left(\omega_{\mathrm{n} \psi}{ }^{\prime}\right):$ :

$$
\omega_{\mathrm{n} \psi}{ }^{\prime}=\omega_{\mathrm{n} \psi} \sqrt{1-\mathrm{D}_{\psi}{ }^{2}}
$$

8. Frekuensi natural terendam $\left(\mathrm{f}_{\mathrm{n} \psi}{ }^{\prime}\right)$ : 


$$
\mathrm{f}_{\mathrm{n} \psi}{ }^{\prime}=\frac{\omega_{\mathrm{n} \psi}}{2 \pi}
$$

9. Rasio kecepatan sudut $\left(r_{\psi}\right)$ :

$$
\mathrm{r}_{\psi}=\frac{\omega}{\omega_{\mathrm{n} \psi}}
$$

10. Amplitudo $\left(\mathrm{A}_{\psi}\right)$ :

$$
\mathrm{A}_{\psi}=\frac{\mathrm{M}_{\mathrm{z}}}{\mathrm{k}_{\psi} \sqrt{\left(1-\mathrm{r}_{\psi}{ }^{2}\right)^{2}+\left(2 \cdot \mathrm{D}_{\psi}\right)^{2}}}
$$

2.2.7 Analisis dinamis dalam arah goyangan pitching Getaran pitching adalah getaran yang mengakibatkan suatu pondasi berputar terhadap sumbu $\mathrm{x}$. Untuk mengetahui getaran tunggal pitching harus dihitung [7]: 1. Radius ekivalen $\left(\mathrm{r}_{\mathrm{p}}\right)$ :

$$
r_{p}=\sqrt[4]{B \cdot L^{3} / 3 \pi}
$$

2. Koefisien pegas $\left(\mathrm{k}_{\mathrm{p}}\right)$ :

$$
\mathrm{k}_{\mathrm{p}}=\frac{8 \cdot \mathrm{G} \cdot \mathrm{r}_{\mathrm{p}}{ }^{3}}{3 \cdot(1-v)}
$$

3. Rasio massa $\left(\mathrm{B}_{\mathrm{p}}\right)$ :

$$
\mathrm{B}_{\mathrm{p}}=\frac{3 \cdot(1-v) \cdot \mathrm{M}_{\mathrm{x}}}{8 \cdot \gamma \cdot \mathrm{r}_{\mathrm{p}}{ }^{3}}
$$

Dengan: $\mathrm{M}_{\mathrm{x}}=$ momen massa mesin terhadap sumbu $\mathrm{x}$ sesuai nilai $\mathrm{I}_{\mathrm{x}}$. $\mathrm{I}_{\mathrm{x}}$ diambil dari Gambar 10 [4, 22].

4. Rasio redaman sesuai lebar pondasi $\left(D_{p}\right)$ :

$$
\mathrm{D}_{\mathrm{p}}=\frac{0,15}{\left(1+\mathrm{B}_{\mathrm{p}}\right) \cdot \sqrt{\mathrm{B}_{\mathrm{p}}}}
$$

5. Frekuensi natural $\left(f_{n p}\right)$ :

$$
f_{n p}=\frac{1}{2 \pi} \cdot \sqrt{\frac{k_{p}}{m}}
$$

6. Frekuensi resonansi $\left(f_{r}\right)$ :

$$
\mathrm{f}_{\mathrm{r}}=\mathrm{f}_{\mathrm{np}} \cdot \sqrt{1-2 \mathrm{D}_{\mathrm{p}}^{2}}
$$

7. Kecepatan sudut $\left(\omega_{\mathrm{np}}\right)$ :

$$
\omega_{\mathrm{np}}=\sqrt{\frac{\mathrm{k}_{\mathrm{p}}}{\mathrm{m}}}
$$

8. Rasio kecepatan sudut $\left(\mathrm{r}_{\mathrm{p}}\right)$ :

$$
r_{p}=\frac{\omega}{\omega_{n p}}
$$

9. Amplitudo $\left(\mathrm{A}_{\mathrm{p}}\right)$ :

$$
A_{p}=\frac{M_{x}}{k_{p} \sqrt{\left(1-r_{p}^{2}\right)^{2}+\left(2 \cdot D_{p}\right)^{2}}}
$$

2.2.8 Koefisien pegas tanah tunggal dan gabungan Kombinasi getaran translasi dan rocking mengakibatkan pondasi memiliki pergerakan translasi dan gaya horizontal tunggal dan gabungan yang mengakibatkan perputaran sudut [13], perhitungan getaran rocking dan horizontal dapat dihitung dengan:

1. Koefisien pegas arah horizontal/lateral $\left(\mathrm{k}_{\mathrm{x}}\right)$ tunggal Persamaan untuk mencari koefisien pegas tanah arah horizontal adalah $[3,10,21]$ :

$\mathrm{k}_{\mathrm{x}}=2(1+v) \cdot \mathrm{G} \cdot \beta_{\mathrm{x}} \cdot \sqrt{\mathrm{B} \cdot \mathrm{L}} \cdot \eta_{\mathrm{x}}$

Dengan: $\beta_{\mathrm{x}}=$ faktor geometri pondasi (Gambar 12)

2. Koefisien pegas tanah rocking $\left(\mathrm{k}_{\phi}\right)$ tunggal

Koefisien pegas tanah rocking dapat dirumuskan sebagai berikut $[13,22]$ :

$$
\mathrm{k}_{\phi}=\frac{\mathrm{G}}{1-v} \cdot \beta_{\phi} \cdot \mathrm{B} \cdot \mathrm{L} \cdot \eta_{\phi}
$$

3. Koefisien pegas tanah horizontal dan rocking $\left(\mathrm{k}_{\mathrm{x} \phi}\right)$ Faktor yang mempengaruhi koefisien pegas tanah

\begin{tabular}{|c|c|c|c|c|c|c|c|c|c|}
\hline \multicolumn{2}{|c|}{ Jenis tanah } & \multirow[b]{2}{*}{$C_{\phi 1}$} & \multirow[b]{2}{*}{$C_{62}$} & \multirow[b]{2}{*}{$\mathrm{C}_{\mathrm{x} 1}$} & \multirow[b]{2}{*}{$\mathrm{C}_{\mathrm{x} 2}$} & \multirow[b]{2}{*}{$S_{01}$} & \multirow{2}{*}{$\mathrm{S}_{02}$} & \multirow[b]{2}{*}{$\mathrm{S}_{\mathrm{xl}}$} & \multirow[b]{2}{*}{$S_{x 2}$} \\
\hline Samping & Dasar & & & & & & & & \\
\hline Lempung & Lempung & 4,3 & 0,7 & 5,1 & 3,2 & 2,5 & 1,8 & 4,1 & 10,6 \\
\hline Lempung & Pasir & 3,3 & 0.5 & 4,7 & 2,8 & 2,5 & 1,8 & 4,1 & 10,6 \\
\hline Pasir & Lempung & 4,3 & 0,7 & 5,1 & 3,2 & 2,5 & 1,8 & 4 & 9,1 \\
\hline Pasir & Pasir & 3,3 & 0,5 & 4,7 & 2,8 & 2,5 & 1,8 & 4 & 9,1 \\
\hline
\end{tabular}
adalah rocking dan horizontal (koefisien crossing). Koefisien pegas tanah rocking dan horizontal dapat dirumuskan $[3,10]$ :

$$
\mathrm{k}_{\mathrm{x} \phi}=-\mathrm{G} \cdot \mathrm{r}_{0}\left(\mathrm{~L} \cdot \mathrm{C}_{\mathrm{xl}}+\frac{\mathrm{G}_{\mathrm{s}}}{\mathrm{G}} \cdot \frac{\mathrm{t}}{\mathrm{r}_{0}}\left(\mathrm{~L}-\frac{\mathrm{t}}{2}\right) \cdot \mathrm{S}_{\mathrm{xl}}\right)
$$

Dengan: $\mathrm{G}=$ modulus geser tanah; $\mathrm{L}=$ titik berat sistem; $\mathrm{C}_{\mathrm{x} 1}=$ konstanta kekakuan dan redaman (Tabel 6); $\mathrm{G}_{\mathrm{s}}=$ modulus geser tanah samping; $\mathrm{G}=$ modulus geser tanah dasar; $\mathrm{t}=$ tinggi/tebal pondasi; $\mathrm{r}_{0}=$ radius ekuivalen rata - rata; $\mathrm{S}_{\mathrm{x} 1}=$ konstanta kekakuan dan redaman (terlihat juga pada Tabel 6).

Tabel 6. Nilai $\mathrm{C}_{\phi 1}, \mathrm{C}_{\phi 2}, \mathrm{C}_{\mathrm{x} 1}, \mathrm{C}_{\mathrm{x} 2}, \mathrm{~S}_{\phi 1}, \mathrm{~S}_{\phi 2}, \mathrm{~S}_{\mathrm{x} 1}, \mathrm{~S}_{\mathrm{x} 2}[3,7]$

2.2.9 Peredam getaran tanah tunggal dan gabungan

1. Redaman arah horizontal/lateral $\left(\mathrm{c}_{\mathrm{x}}\right)$ tunggal

Redaman arah horizontal dapat dirumuskan $[4,8]$ :

$-\mathrm{c}_{\mathrm{x}}=\mathrm{r}_{0}{ }^{4} \sqrt{\gamma \cdot \mathrm{G}}\left(\mathrm{C}_{\mathrm{x} 2}+\frac{\mathrm{G}_{\mathrm{s}}}{\mathrm{G}} \cdot \frac{\mathrm{t}}{\mathrm{r}_{0}} \sqrt{\frac{\mathrm{G}_{\mathrm{s}} \cdot \gamma_{\mathrm{s}}}{\mathrm{G} \cdot \gamma}} \cdot \mathrm{S}_{\mathrm{x} 2}\right)$

Dengan: $\gamma=$ berat volume tanah dasar; $\gamma_{\mathrm{s}}=$ berat volume tanah samping; $S_{\mathrm{x} 2}$ dan $\mathrm{C}_{\mathrm{x} 2}=$ konstanta kekakuan dan redaman (Tabel 6).

2. Redaman arah rocking $\left(\mathrm{c}_{\phi}\right)$

Redaman arah rocking tunggal dapat dirumuskan sebagai berikut $[4,10]$ :

$$
-\mathrm{c}_{\phi}=\mathrm{r}_{0}^{4} \sqrt{\gamma \cdot \mathrm{G}}\left(\begin{array}{l}
\mathrm{C}_{\phi 2}+\left(\frac{\mathrm{L}}{\mathrm{r}_{0}}\right)^{2}+\frac{\mathrm{t}}{\mathrm{r}_{0}} \sqrt{\frac{\mathrm{G}_{\mathrm{s}} \cdot \gamma_{\mathrm{s}}}{\mathrm{G} \cdot \gamma}} \\
{\left[\mathrm{S}_{\phi 2}+\left(\frac{\mathrm{t}^{2}}{3 \cdot \mathrm{r}_{0}{ }^{2}}+\frac{\mathrm{L}^{2}}{\mathrm{r}_{0}{ }^{2}}+\frac{\mathrm{t} \cdot \mathrm{L}}{\mathrm{r}_{0}{ }^{2}}\right) \cdot \mathrm{S}_{\mathrm{x} 2}\right]}
\end{array}\right)
$$

Dengan: $\mathrm{C}_{\phi 2} ; \mathrm{S}_{\phi 2}$; dan $\mathrm{S}_{\mathrm{x} 2}=$ faktor kekakuan dan redaman (Tabel 6).

3. Redaman arah horizontal/lateral dan rocking $\left(c_{x \phi}\right)$ Redaman arah horizontal/lateral dan rocking dapat dirumuskan $[4,10]$ :

$$
-\mathrm{c}_{\mathrm{x} \phi}=-\mathrm{r}_{0}^{2} \sqrt{\gamma \cdot \mathrm{G}}\left(\mathrm{L} \cdot \mathrm{C}_{\mathrm{x} 2}+\frac{\mathrm{t}}{\mathrm{r}_{0}} \sqrt{\frac{\mathrm{G}_{\mathrm{s}} \cdot \gamma_{\mathrm{s}}}{\mathrm{G} \cdot \gamma}} \cdot\left(\mathrm{L}-\frac{\mathrm{t}}{2}\right) \mathrm{S}_{\mathrm{x} 2}\right)
$$

Dengan: $\mathrm{S}_{\mathrm{x} 2}$ dan $\mathrm{C}_{\mathrm{x} 2}=$ konstanta kekakuan dan redaman (Tabel 6).

Besar amplitudo gabungan rocking dan horizontal dapat dihitung dengan memasukkannya ke dalam persamaan matriks $[4,10]$ :

$$
\left[\begin{array}{cccc}
\mathrm{A} & \mathrm{B} & \mathrm{C} & -\mathrm{D} \\
-\mathrm{B} & \mathrm{A} & \mathrm{D} & \mathrm{C} \\
\mathrm{C} & -\mathrm{D} & \mathrm{E} & \mathrm{F} \\
\mathrm{D} & \mathrm{C} & -\mathrm{F} & \mathrm{E}
\end{array}\right]\left[\begin{array}{c}
\mathrm{A}_{\mathrm{x} 1} \\
\mathrm{~A}_{\mathrm{x} 2} \\
\mathrm{~A}_{\phi 1} \\
\mathrm{~A}_{\phi 2}
\end{array}\right]=\left[\begin{array}{c}
-\mathrm{P}_{0} \\
0 \\
-\mathrm{M}_{0} \\
0
\end{array}\right]
$$

Atau: $[\mathrm{S}]\{\mathrm{A}\}=\{\mathrm{H}\}$

Dengan ketentuan sebagai berikut:

$$
\begin{aligned}
& \mathrm{A}=\left(\mathrm{m} \cdot \omega^{2}-\mathrm{k}_{\mathrm{x}}\right) \\
& \mathrm{B}=\mathrm{C}_{\mathrm{x}} \cdot \omega
\end{aligned}
$$

Journal of Applied Civil Engineering and Infrastructure Technology (JACEIT) 


$$
\begin{aligned}
& \mathrm{C}=\mathrm{k}_{\mathrm{x}} \cdot \mathrm{L}-\mathrm{k}_{\mathrm{x} \phi} \\
& \mathrm{D}=\left(\mathrm{C}_{\mathrm{x}} \cdot \mathrm{L}-\mathrm{C}_{\mathrm{x} \phi}\right) \cdot \omega \\
& \mathrm{E}=\mathrm{I} \cdot \mathrm{C} \phi \cdot \gamma \cdot \omega^{2}-\mathrm{k} \phi+2 \cdot \mathrm{k}_{\mathrm{x} \phi} \cdot \mathrm{L}-\mathrm{k}_{\mathrm{x}} \cdot \mathrm{L}^{2} \\
& \mathrm{D}=\left(\mathrm{C}_{\phi}-2 \cdot \mathrm{C}_{\mathrm{x} \phi}+\mathrm{C}_{\mathrm{x}} \cdot \mathrm{L}^{2}\right) \cdot \omega
\end{aligned}
$$

2.2.10 Desain karet/pegas peredam arah vertikal [8]

1. Kekuatan pegas peredam $\left(\mathrm{k}_{\mathrm{zt}}\right)$

$$
\mathrm{k}_{\mathrm{zt}}=\mathrm{k}_{\mathrm{s}} \cdot \alpha
$$

Dengan: $\mathrm{k}_{\mathrm{z}}=$ konstanta pegas arah vertikal; $\alpha=$ Rasio dinamik (rasio antara dinamis dan statis $=1,30$ ); $\mathrm{k}_{\mathrm{s}}=2$ konstanta pegas statis.

2. Frekuensi karet/pegas peredam $\left(\mathrm{f}_{\mathrm{dzt}}\right)$

$$
\mathrm{f}_{\mathrm{dzt}}=\frac{60}{2 \pi} \cdot \sqrt{\frac{\mathrm{k}_{\mathrm{z}} \cdot \sum \text { karet.g }}{\mathrm{W}}}
$$

3. Faktor transmisi (transmibility factor)

$$
T_{r}=\frac{1}{\left[\frac{f}{f_{d z t}}\right]^{2}-1}
$$

4. Beban dinamis tersalur

$$
\mathrm{W}_{\mathrm{din}}=\mathrm{F}_{\mathrm{din}} \cdot \mathrm{T}_{\mathrm{r}}
$$

2.2.11 Desain karet/pegas peredam arah horizontal [8]

1. Kekuatan pegas peredam $\left(\mathrm{k}_{\mathrm{xt}}\right)$

$$
\mathrm{k}_{\mathrm{xt}}=\frac{1}{7} \mathrm{k}_{\mathrm{zt}}
$$

2. Untuk frekuensi karet/pegas peredam; faktor transmisi; beban dinamis tersalur adalah sama atau identik dengan arah vertikal.

\section{Peredam getaran (vibration isolator)}

Peredam Getaran (vibration isolator)adalah suatu material yang sifatnya dapat meredam atau menahan getaran. Peredam getaran sendiri terbuat dari berbagai macam bahan seperti: natural rubber, neoprone, zat fluida dan sebagainya. Dalam kasus ini generator set digunakan peredam dengan menggunakan peredam getaran berbahan natural rubber. Analisis pemilihan yang digunakan adalah $[10,15,22]$. Dalam pemilihan karet peredam didasarkan atas nilai atau besarnya pengaruh karet di dalam meredam getaran yang terjadi akibat operasi mesin generator set. Berikut faktor transmisi (transmibility factor) dirumuskan [15]:

$\mathrm{T}_{\mathrm{r}}=\frac{\sqrt{1+(2 . \mathrm{D})^{2}}}{\sqrt{\left(1-\mathrm{r}^{2}\right)+(2 . \mathrm{D})^{2}}}$

Dengan: $\mathrm{D}=$ Rasio redaman total; $\mathrm{r}=$ Rasio frekuensi; $\mathrm{T}_{\mathrm{r}}=$ faktor transmisi. Nilai $\mathrm{T}_{\mathrm{r}}$ direncanakan $2 \%$ atau 0.02 , maka nilai redaman diasumsikan $\mathrm{D}=0$ untuk mempermudah perhitungan, maka persamaannya menjadi:

$$
T_{r}=\frac{1}{\left[1-\left(\frac{f}{f_{n}}\right)^{2}\right]}
$$

2.2.10 Angka keamanan untuk statis dan dinamis

Dalam perencanaan pondasi mesin beberapa faktor keamanan ditinjau berdasarkan aspek-aspek lingkungan Berikut tabel dan grafik untuk nilai keamanan perencanaan pondasi mesin.

1. Syarat keamanan terhadap daya dukung dan penurunan [22] statis terhadap dinamis:

a. Tegangan statis $<50 \%$ daya dukung izin $\left(\mathrm{q}_{\text {all }}\right)$

b. Tegangan dinamis $<75 \%$ daya dukung izin ( $\mathrm{q}_{\text {all }}$ )

c. Frekuensi operasi harus kurang lebih $20 \%$ dari frekuensi resonansi.

2. Syarat keamanan amplitudo vertikal [15]

3. Syarat keamanan amplitudo horizontal [2, 3]

4. Syarat keamanan menurut KepMenNeg KLH [12]

5. Syarat keamanan seluruh struktur pondasi [15]

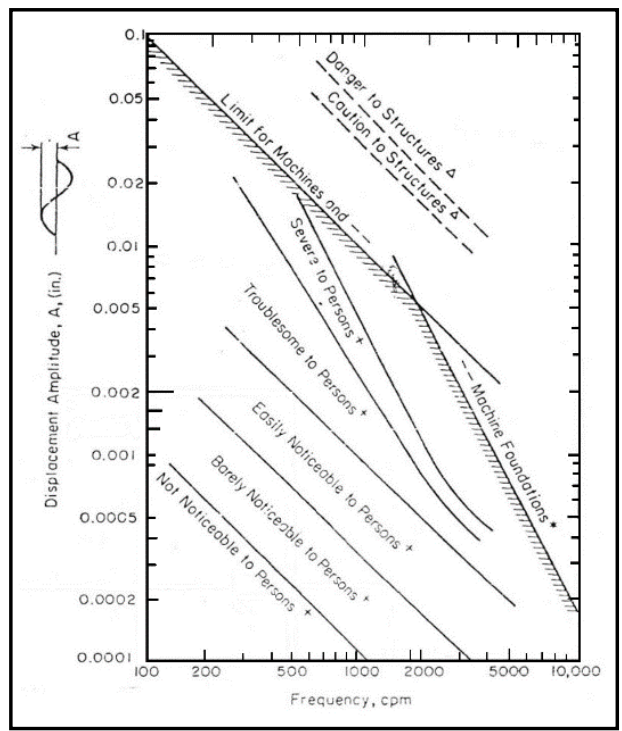

Gambar 13. Amplitudo izin untuk getaran vertikal [13]

Tabel 7. Kriteria kecepatan getaran horizontal [2]

\begin{tabular}{|c|c|}
\hline $\begin{array}{c}\text { Kecepatan horizontal } \\
\text { (in/sec) }\end{array}$ & Keadaan mesin \\
\hline$<0,005$ & Extremely smooth \\
\hline $0,005-0,010$ & Very smooth \\
\hline $0,10-0,02$ & Smooth \\
\hline $0,02-0,04$ & Very good \\
\hline $0,04-0,08$ & Good \\
\hline $0,08-0,16$ & Fair \\
\hline $0,16-0,315$ & Slightly rough \\
\hline $0,315-0,630$ & Rough \\
\hline$>0,63$ & Very rough \\
\hline
\end{tabular}

Getaran pada struktur yang berdekatan dapat diabaikan jika amplitudo yang terjadi pada pondasi kurang dari 0,2 $\mathrm{mm}$ atau $\mathrm{A}_{\mathrm{ijin}} \leq 0,2 \mathrm{~mm}$. Kriteria design pondasi mesin berdasarkan beban statis yaitu pondasi tidak boleh mengalami penurunan tanah yang berlebihan [15]. Kriteria design pondasi mesin berdasarkan beban dinamis adalah pondasi tidak boleh mengalami resonansi dan getaran yang diakibatkan oleh mesin tidak boleh menganggu ataupun memberi efek buruk terhadap orang dan peralatan di sekitarnya.

Journal of Applied Civil Engineering and Infrastructure Technology (JACEIT) 


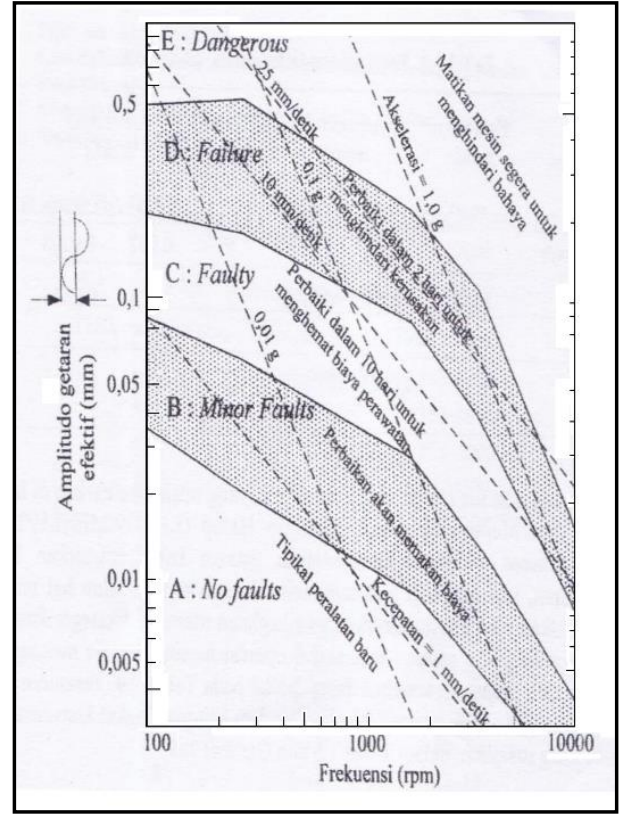

Gambar 14. Kriteria getaran/vibrasi izin untuk pondasi mesin [2]

6. Syarat keamanan lainnya

Penurunan yang diijinkan untuk pondasi terpisah pada tanah lempung, yaitu sebesar $65 \mathrm{~mm}$ [19].

Tabel 8. Baku tingkat getaran mekanik untuk kenyamanan dan kesehatan $\left(10^{-6} \mathrm{~m}\right)[12]$

\begin{tabular}{|ccccc|}
\hline \multirow{5}{*}{ Frekuensi } & \multicolumn{5}{c|}{ Nilai tingkat getaran $\left(10^{-6}\right.$ meter $)$} \\
& $\begin{array}{c}\text { Tidak } \\
\text { Mengganggu }\end{array}$ & Mengganggu Tidak Nyaman Menyakitkan \\
\hline 4 & $<100$ & $100-500$ & $>500-1000$ & $>1000$ \\
\hline 5 & $<80$ & $80-350$ & $>350-100$ & $>1000$ \\
\hline 6.3 & $<70$ & $70-275$ & $>275-1000$ & $>1000$ \\
\hline 8 & $<50$ & $50-160$ & $>160-500$ & $>500$ \\
\hline 10 & $<37$ & $37-120$ & $>120-300$ & $>300$ \\
\hline 12.5 & $<32$ & $32-90$ & $>90-220$ & $>220$ \\
\hline 16 & $<25$ & $25-60$ & $>60-120$ & $>120$ \\
\hline 20 & $<20$ & $20-40$ & $>40-85$ & $>85$ \\
\hline 25 & $<17$ & $17-30$ & $>30-50$ & $>50$ \\
\hline 31.5 & $<12$ & $12-20$ & $>20-30$ & $>30$ \\
\hline 40 & $<9$ & $9-15$ & $>15-20$ & $>20$ \\
\hline 50 & $<8$ & $8-12$ & $>12-15$ & $>15$ \\
\hline 3 & $<6$ & $6-9$ & $>9-12$ & $>12$ \\
\hline
\end{tabular}

Tabel 9. Baku tingkat getaran mekanik untuk kenyamanan dan kesehatan (mm/detik) [12]

\begin{tabular}{|c|c|c|c|c|c|c|}
\hline \multicolumn{2}{|c|}{ Getaran } & \multirow{2}{*}{$\begin{array}{l}\text { Frekuensi- } \\
\text { (Hz) }\end{array}$} & \multicolumn{4}{|c|}{ Batas getaran, peak, $\mathrm{mm} /$ detik } \\
\hline Parameter & Satuan & & $\begin{array}{c}\text { Kategori } \\
\text { A } \\
\end{array}$ & $\begin{array}{c}\text { Kategori } \\
\text { B } \\
\end{array}$ & $\begin{array}{c}\text { Kategori } \\
\mathrm{C} \\
\end{array}$ & $\begin{array}{c}\text { Kategori } \\
\text { D }\end{array}$ \\
\hline \multirow{2}{*}{$\begin{array}{c}\text { Kecepatan } \\
\text { Getaran }\end{array}$} & \multirow{2}{*}{$\mathrm{mm} / \mathrm{detik}$} & 4 & $<2$ & $<2-27$ & $>27-140$ & $>140$ \\
\hline & & 5 & $<7.5$ & $<7.5-25$ & $>25-130$ & $>130$ \\
\hline \multirow[t]{10}{*}{ Frekuensi } & $\mathrm{Hz}$ & 6.3 & $<7$ & $<7-21$ & $>21-110$ & $>110$ \\
\hline & & 8 & $<6$ & $<6-19$ & $>19-100$ & $>100$ \\
\hline & & 10 & $<5.2$ & $<5,2-16$ & $>16-90$ & $>90$ \\
\hline & & 12.5 & $<4.8$ & $<4.8-15$ & $>15-80$ & $>80$ \\
\hline & & 16 & $<4$ & $<4-14$ & $>14-70$ & $>70$ \\
\hline & & 20 & $<3.8$ & $<3.8-12$ & $>12-67$ & $>67$ \\
\hline & & 25 & $<3.2$ & $<3.2-10$ & $>10-60$ & $>60$ \\
\hline & & 31.5 & $<3$ & $<3-9$ & $>9-53$ & $>53$ \\
\hline & & 40 & $<2$ & $<2-8$ & $>8-50$ & $>50$ \\
\hline & & 50 & $<1$ & $<1-7$ & $>7-42$ & $>42$ \\
\hline
\end{tabular}

\section{Hasil dan Pembahasan}

\subsection{Spesifikasi mesin Genset}

Data spesifikasi mesin yang dipilih dijadikan sebagai data perhitungan beban dinamis pada analisis dan perencanaan pondasi dangkal dinamis. Berikut disajikan data spesifikasi mesin generator set lengkap yang digunakan di dalam perencanaan sebagaimana diperlihatkan dalam Gambar 1, yaitu: merk: Perkins (USA); model: 1306A-E87TAG4; engine speed: 1500 rpm; engine power output at rated: $255 \mathrm{kWm}$; cooling: radiator cooled; total displacement : 8.7 liter; compresion ratio: 16.9 : 1; oil capacity: 26.4 liter; coolant capacity: 24.2 liter; massa motor : $377 \mathrm{~kg}$; standby: $250 \mathrm{kVA} / 200 \mathrm{~kW}$; berat : $2075 \mathrm{~kg}$; tinggi : $1.716 \mathrm{~m}$; panjang : $2.909 \mathrm{~m}$; lebar : $0.98 \mathrm{~m}$ [26].

\subsection{Penyusunan parameter tanah}

Data tanah yang digunakan pada perencanaan pondasi mesin adalah data hasil korelasi berdasarkan data CPT (Tabel 10), oleh karena data lain tidak tersedia, seperti: angka pori inisial / awal $\left(\mathrm{e}_{0}\right)=1,90$; indeks kompresi / pemampatan konsolidasi $\left(\mathrm{C}_{\mathrm{c}}\right)=1,87$; modulus geser $(\mathrm{G})$ $=3,5.10^{6} \mathrm{~kg} / \mathrm{m}^{2}$; redaman (D) internal lapisan tanah lempung diambil $=0,05$ dan sebagainya menggunakan tabel-tabel di dalam pembahasan sebelumnya. Hasilhasil korelasi diperlihatkan Tabel 11.

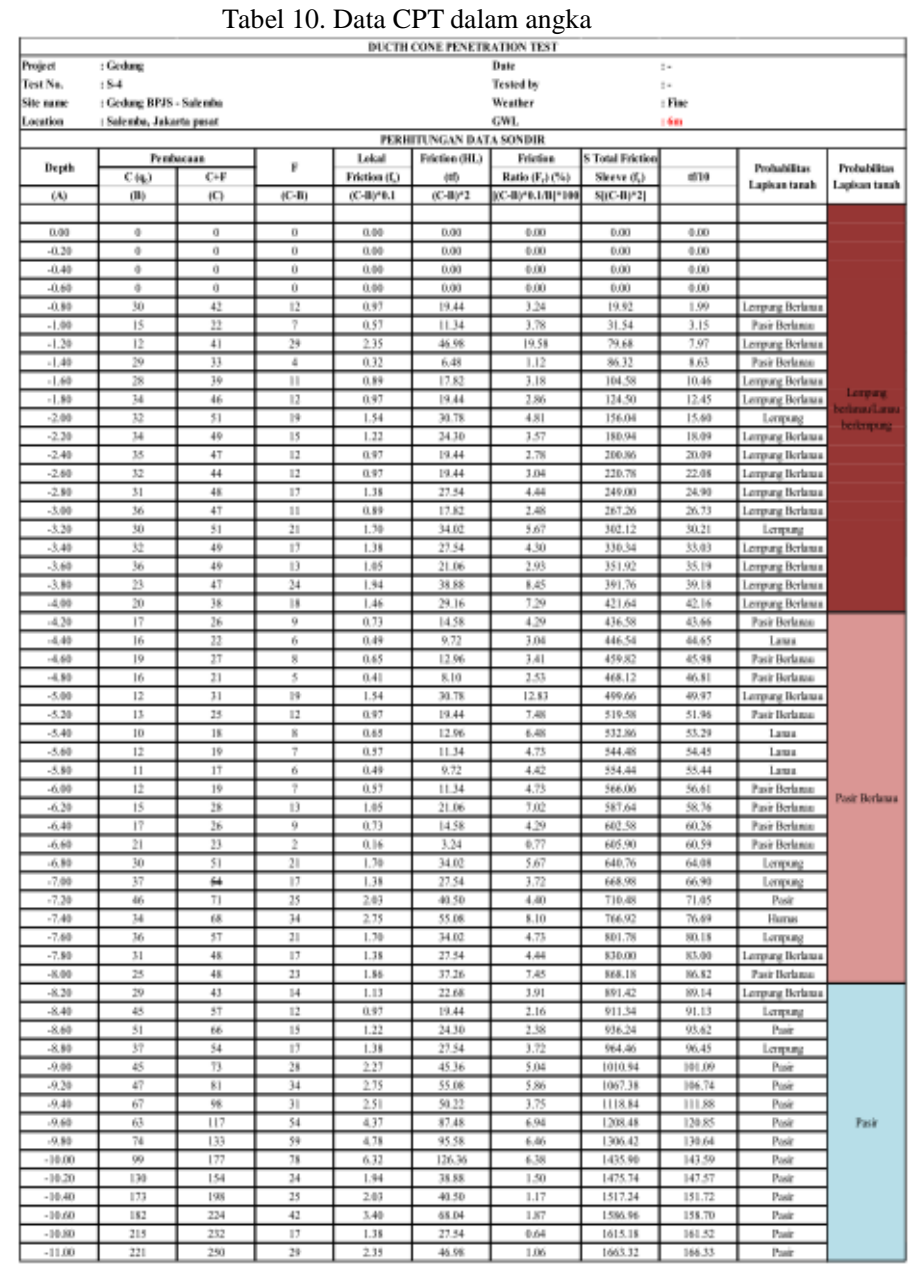

Journal of Applied Civil Engineering and Infrastructure Technology (JACEIT) 
Tabel 11 Parameter tanah tipikal yang digunakan di dalam analisis dan perencanaan pondasi dangkal mesin Genset

\begin{tabular}{|c|c|c|c|}
\hline \multicolumn{3}{|c|}{ Lapisan 1: Lempung berlanau/lanau berlempung } & \multirow{3}{*}{$\begin{array}{l}\text { Kedalaman: } 0,00-2,00[\mathrm{~m}] \\
\mathrm{q}_{\mathrm{c}}(\mathrm{sondir} / \mathrm{CPT})=0-24\left[\mathrm{~kg} / \mathrm{cm}^{2} \mid\right. \\
\mathrm{kN} / \mathrm{m}^{3}\end{array}$} \\
\hline & Sondir/CPT berdasarkan uji & lalah posisi S-4 & \\
\hline 1. & Bcrat volume tanah asli $\left(\gamma_{0}\right)$ & $16-17$ & \\
\hline 2. & Berat volume tanah jenuh $\left(\gamma_{\text {sat }}\right)$ & $17-18$ & $\mathrm{kN} / \mathrm{m}^{3}$ \\
\hline 3. & Pstrmeabilitas (k) & $8,6.10^{-9}-1,7.10^{-8}$ & m/detik \\
\hline 4. & Modulus elastisitas Young (E) & $32,7-130,9$ & $\mathrm{kNim}{ }^{2}$ \\
\hline 5. & Angka Poison (v) & $0,4-0,5$ & - \\
\hline 6. & Kohesi (c) & $29,4-39,2$ & $\mathrm{kN} / \mathrm{m}^{2}$ \\
\hline 7. & Sudut geser dalam $(\phi)$ & $5,0-7,5$ &. \\
\hline \multicolumn{3}{|c|}{ Lapisan 2: Lanau berpasir/lanau } & Kedalaman: $2,20-4,20[\mathrm{~m}]$ \\
\hline \multicolumn{3}{|c|}{ Data Sondir / CPT berdasarkan uji lapangan adalah posisi S-4 } & $q_{\mathrm{c}}($ sondir $/ \mathrm{CPT})=20-36\left|\mathrm{~kg} / \mathrm{cm}^{2}\right|$ \\
\hline 1. & Berat volume tanah asli $\left(y_{i}\right)$ & $\begin{array}{r}17-18 \\
\end{array}$ & $\mathrm{kN} / \mathrm{m}^{3}$ \\
\hline 2. & Berat volume tanah jenuh $\left(\gamma_{\text {sat }}\right)$ & $18-19$ & $\mathrm{kN} / \mathrm{m}^{3}$ \\
\hline 3. & Permcabilitas $(\mathrm{k})$ & $6,7 \cdot 10^{6}-2,9 \cdot 10^{7}$ & midctik \\
\hline 4. & Modulus elastisitas Young (E) & $60,7-288,3$ & $\mathrm{kN} / \mathrm{m}^{2}$ \\
\hline 5. & Angka Poison (v) & $0,3-0,4$ & - \\
\hline 6. & Kohesi (c) & $19,6-40,0$ & $\mathrm{kN} / \mathrm{m}^{2}$ \\
\hline 7. & Sudut gescr dalam (o) & $8,5-10,5$ & 0 \\
\hline \multicolumn{3}{|c|}{ Lapisan 3: Lempung berlanau/lanau herlempung } & Kedalaman: $4,20-6,20[\mathrm{~m}]$ \\
\hline \multicolumn{3}{|c|}{ Data Sondir/CPT berdasarkan uji lapangan adalah posisi S-4 } & 4c $($ sondir $/ \mathrm{CPT})=20-36\left|\mathrm{~kg} / \mathrm{cm}^{2}\right|$ \\
\hline 1. & Berat volume tanah asli $\left(\gamma_{t}\right)$ & $17-18$ & $\mathrm{kN} / \mathrm{m}^{3}$ \\
\hline 2. & Berat volume tanah jenuh $\left(\gamma_{\mathrm{yst}}\right)$ & $18-19$ & $\mathrm{kN} / \mathrm{m}^{3}$ \\
\hline 3. & Permeabilitas $(\mathrm{k})$ & $8,1.10^{-9}-5,3 \cdot 10^{-9}$ & midetik \\
\hline 4. & Modulus clastisitas Young (E) & $20,7-152,7$ & $\mathrm{kN} / \mathrm{m}^{2}$ \\
\hline 5. & Angka Poison (12) & $0,4-0,5$ & - \\
\hline 6. & Kohesi (c) & $39,2-48,9$ & $\mathrm{kNim}{ }^{2}$ \\
\hline 7. & Sudut geser dalam $(\phi)$ & $6,5-11,2$ & 0 \\
\hline \multicolumn{3}{|c|}{ Lapisan 4: Pasir kelanauan/lanau kepasiran } & Kedalaman: $6,20-11,20|\mathrm{~m}|$ \\
\hline \multicolumn{3}{|c|}{ Data Sondir / CPT berdasarkan uji lapangan adalah posisi S-4 } & $q_{\mathrm{c}}($ sondir $/ \mathrm{CPT})=20-36\left[\mathrm{~kg} / \mathrm{cm}^{2}\right]$ \\
\hline 1. & Berat volume tanah asli $\left(\gamma_{i}\right)$ & $17-18$ & $\mathrm{kN} / \mathrm{m}^{3}$ \\
\hline 2. & Berat volume tanah jenulh $\left(\gamma_{\mathrm{yet}}\right)$ & $18-19$ & $\mathrm{kN} / \mathrm{m}^{3}$ \\
\hline 3. & Permeabilitas (k) & $3,1.10^{-6}-2,7.10^{5}$ & midetik \\
\hline 4. & Modulus clastisitas Young (E) & $390,7-663,9$ & $\mathrm{kN} / \mathrm{m}^{2}$ \\
\hline 5. & Angka Poison (v) & $0,1-0,4$ & - \\
\hline 6. & Kohesi (c) & $2,2-7,3$ & $\mathrm{kN} / \mathrm{m}^{2}$ \\
\hline 7. & Sudut gescr dalam ( $($ ) & $19,5-37,8$ & a \\
\hline
\end{tabular}

\subsection{Data hasil perhitungan dinamis}

Data hasil perhitungan dinamis dalam arah gerak vertikal; horizontal; arah goyangan rocking; arah gerak longitudinal; arah goyangan yawing; dan arah goyangan pitching diperlihatkan dalam Tabel 12.

Tabel 12. Data hasil perhitungan dinamis dalam arah gerak vertikal; horizontal; arah goyangan rocking; arah gerak longitudinal; arah goyangan yawing; dan arah goyangan pitching
3.4 Pergerakan (displacement) statis dan dinamis:

1. Kontrol penurunan tanah pada kondisi statis:

Mengacu pada batas penurunan maksimum [19, 27], ternyata penurunan total yang terjadi masih dalam batas aman yaitu sebesar 0,49 $\mathrm{mm}<0,50 \mathrm{~mm}$.

2. Kontrol keamanan gerakan tunggal (single) dan gabungan (couple mode) pada kondisi dinamis: Kontrol keamanan diperlihatkan dalam Tabel 13.

Tabel 13. Kontrol keamanan untuk gerakan tunggal dan gabungan (couple mode)

\begin{tabular}{|c|c|c|}
\hline \multirow{2}{*}{$\begin{array}{l}\text { Metode } \\
\text { analisis }\end{array}$} & \multicolumn{2}{|c|}{ Tipe getaran } \\
\hline & Tunggal & $\begin{array}{c}\text { Gabungan } \\
\text { (couple mode) }\end{array}$ \\
\hline 1 & 2 & 3 \\
\hline$[15]$ & $\begin{array}{c}\left(\mathrm{A}_{\mathrm{z}}\right)=1,0 \cdot 10^{-4} \\
\text { (inchi) }\end{array}$ & $\begin{array}{c}\left(\mathrm{A}_{2}\right)=2,6 \cdot 10^{-4} \\
\text { (inchi) }\end{array}$ \\
\hline Kesimpulan & $\begin{array}{c}\text { "Not noticeable to } \\
\text { Persons" }\end{array}$ & $\begin{array}{c}\text { "Not noticeable to } \\
\text { Persons" }\end{array}$ \\
\hline [3] & $\begin{array}{c}(v)=0,02 \\
(\text { inchi/detik) }\end{array}$ & $\begin{array}{c}(v)=0,04 \\
(\text { inchi/detik) }\end{array}$ \\
\hline Kesimpulan & "Extremely smooth" & "Smooth" \\
\hline$[2]$ & $\begin{array}{c}\left(\mathrm{A}_{\mathrm{z}}\right)=2,6 \cdot 10^{-4} \\
(\mathrm{~mm})\end{array}$ & $\begin{array}{c}\left(\mathrm{A}_{\mathrm{z}}\right)=6,6 \cdot 10^{-4} \\
(\mathrm{~mm})\end{array}$ \\
\hline Kesimpulan & "No faults" & "No faults" \\
\hline [12] & $\begin{array}{c}\left(\mathrm{A}_{\mathrm{z}}\right)=2,6 \cdot 10^{-4} \\
(\mathrm{~mm}) \\
\left(\mathrm{A}_{\mathrm{x}}\right)=3,9 \cdot 10^{-3} \\
(\mathrm{~mm}) \\
\left(v_{\text {vertikal }}\right)=0,4 \\
(\mathrm{~mm} / \text { detik }) \\
\left(v_{\text {lateral }}\right)=0,02 \\
(\mathrm{~mm} / \text { detik })\end{array}$ & $\begin{array}{c}\left(\mathrm{A}_{\mathrm{z}}\right)=6,6 \cdot 10^{-4} \\
(\mathrm{~mm}) \\
\left(\mathrm{A}_{\mathrm{x}}\right)=3,2 \cdot 10^{-3} \\
(\mathrm{~mm}) \\
\left(v_{\text {vertikal }}\right)=1,1 \\
(\mathrm{~mm} / \text { detik }) \\
\left(v_{\text {lateral }}\right)=0,02 \\
(\mathrm{~mm} / \text { detik })\end{array}$ \\
\hline Kesimpulan & $\begin{array}{c}\text { "Kategori } A= \\
\text { tidak mengganggu } \\
\text { dan tidak } \\
\text { merusak" }\end{array}$ & $\begin{array}{c}\text { "Kategori } A= \\
\text { tidak mengganggu } \\
\text { dan tidak } \\
\text { merusak" }\end{array}$ \\
\hline
\end{tabular}

\begin{tabular}{|c|c|c|c|c|c|c|c|c|c|c|c|c|c|}
\hline \multicolumn{14}{|c|}{ Jalam aralt gerakan vertikal } \\
\hline $\begin{array}{l}r_{e} \\
(m i)\end{array}$ & $\eta$ & $\begin{array}{c}k \\
\text { (kgim) }\end{array}$ & B. & $\mathbf{a}_{2}$ & b. & Diauth & $\begin{array}{c}\Gamma_{\text {.. }} \\
(\mathrm{H}>)\end{array}$ & $\underset{(H x)}{r}$ & $\begin{array}{c}F_{1} \\
\text { (kog) }\end{array}$ & $\mathrm{T}$ & $\begin{array}{c}m_{e \varepsilon} \\
\text { (ruliset) }\end{array}$ & $r$ & $\stackrel{A}{(m)}$ \\
\hline 1 & 2 & .1 & 4 & 5 & 6 & ? & 8 & 9 & 10 & II & 12 & 13 & 14 \\
\hline 1.4 & 1.1 & $4,4.10^{\circ}$ & 0,3 & 1.4 & 1.1 & 1,1 & 31,5 & 4.5 & 211 & 11,2 & 197,6 & 0.8 & $2,8.10^{\circ}$ \\
\hline \multicolumn{14}{|c|}{ Dalam arah nerakase hurizun|지 } \\
\hline $\begin{array}{l}r, \\
\text { (ai) }\end{array}$ & $\eta_{2}$ & $\begin{array}{c}k \\
\text { (hwimi) }\end{array}$ & B. & $R_{0}$ & D. & Dieth & $\begin{array}{c}\mathrm{I.x} \\
\langle\mathrm{Hzl}\end{array}$ & $\begin{array}{c}\mathrm{L} \\
(\mathrm{H} \text { e })\end{array}$ & $\begin{array}{c}F_{1} \\
\left(k_{n}\right)\end{array}$ & $\mathrm{T}$ & $\begin{array}{c}m_{t c} \\
\text { (rail:sec) }\end{array}$ & $r$ & $\begin{array}{c}A_{1} \\
(m i)\end{array}$ \\
\hline 1,4 & 1.4 & 29.16 & 0,4 & 2,11 & A.S & 18.9 & $2: 5$ & 3.6 & 211 & 13,8 & 161.1 & 1.97 & $3,9.10^{\circ}$ \\
\hline \multicolumn{14}{|c|}{ Dilam arah Levallnan ruching } \\
\hline $\begin{array}{l}\mathrm{r}_{\mathrm{z}} \\
(\mathrm{m})\end{array}$ & $\eta_{\mathrm{z}}$ & $\begin{array}{c}k_{j} \\
\text { (kgim) }\end{array}$ & $\mathrm{B}_{\mathrm{z}}$ & $\mathrm{Tte}_{\mathrm{e}}$ & $\mathrm{D}_{2}$ & Dientit & $\mathrm{f}_{\mathrm{f}+}$ & $\begin{array}{c}\mathrm{C} \\
(\mathrm{He})\end{array}$ & 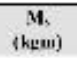 & $\mathrm{T}$ & $\underset{\text { (ruiliset) }}{m_{0,}}$ & 5 & $\begin{array}{c}A_{t} \\
\text { (Irad) }\end{array}$ \\
\hline 1,2 & 1.4 & 4.7 .10 & $60, i$ & 1.2 & 0.5 & 0.9 & 5,1 & 7.2 & 109 & :5.9 & 205.1 & 1.8 & $1,6.10^{-0}$ \\
\hline \multicolumn{14}{|c|}{ Ikalam araht gerakam lonuilmdinal } \\
\hline (a) & $\eta$ & $\begin{array}{c}k \\
\text { (kmimi) }\end{array}$ & B. & re. & D. & Dietii & $\begin{array}{c}\mathrm{I} . \\
\langle\mathrm{H} 2\rangle\end{array}$ & $\begin{array}{c}\Gamma \\
\left(\mathrm{H}_{2}\right)\end{array}$ & $\begin{array}{l}\text { F. } \\
\text { (bor) }\end{array}$ & $\mathrm{r}$ & $\begin{array}{c}m_{7} \\
\text { (radlixic) }\end{array}$ & $r$ & A \\
\hline 1,4 & in & $2,6.10^{4}$ & 0,05 & $a$ & 1.4 & 1,4 & 24,2 & 0 & 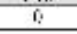 & a & 152.2 & $\theta$ & a \\
\hline \multicolumn{14}{|c|}{ Dalam arab Lovaüan jwringy } \\
\hline $\begin{array}{l}k_{s} \\
\text { (m) }\end{array}$ & $r_{2}$ & $\begin{array}{c}\mathrm{k} \\
(\mathrm{kg} / \mathrm{m})\end{array}$ & Th. & $\alpha$ & $\mathrm{D}_{3}$ & Dieufi & $f_{(I x)}$ & 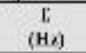 & $\begin{array}{c}\mathrm{Mr}_{\mathrm{s}} \\
\text { (kygm) }\end{array}$ & $\mathrm{T}$ & $\underset{\text { (ruilisec) }}{a_{1 / 4}}$ & $r$ & (rad) \\
\hline 1,5 & a & $6.6 .10^{\circ}$ & 0,1 & $a$ & 0.4 & 1.4 & 38,5 & $1:$ & $i$ & $\pi$ & 242.6 & is & a \\
\hline \multicolumn{14}{|c|}{ Ibalam arah goyangan pidcrimg } \\
\hline $\begin{array}{l}r_{1} \\
\text { (m) }\end{array}$ & itr & $\begin{array}{c}\text { k, } \\
(\text { kimim) }\end{array}$ & B, & $\alpha_{k}$ & D, & D.et+1 & $f_{\langle *}$ & $\begin{array}{c}f \\
f(H) \\
(H)\end{array}$ & $\begin{array}{c}\mathrm{M}_{1} \\
\langle\mathrm{KLmij}\end{array}$ & $\mathrm{T}$ & $\begin{array}{c}\omega_{a n} \\
\text { (ruil'sec) }\end{array}$ & $\mathrm{r}$ & (rasil) \\
\hline 1,2 & i & $3,0.10^{\circ}$ & 0,$0 ;$ & $a$ & 0.5 & 0,9 & 26,2 & 1. & i. & $\pi$ & $16 \ldots . .1$ & D & $\pi$ \\
\hline \multicolumn{14}{|c|}{ 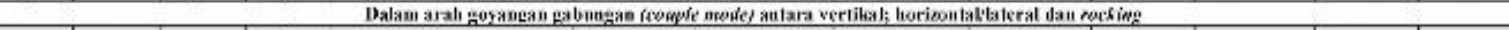 } \\
\hline (iv) & $\underset{(\mathrm{mi}}{\mathrm{r}_{\mathrm{k}}}$ & $\begin{array}{l}r_{n,} \\
(m)\end{array}$ & $\begin{array}{c}h_{1} \\
\text { (hig'm) }\end{array}$ & 4 & $\begin{array}{c}\text { kus } \\
\text { ilogim.iket) }\end{array}$ & (liq.m.tlet) & $\begin{array}{c}c_{v} \\
\text { (kig.det) }\end{array}$ & $\begin{array}{c}\mathrm{c} \\
\text { (kpidet) }\end{array}$ & $\begin{array}{l}A_{11} \\
\text { (ia) }\end{array}$ & $\begin{array}{l}\text { Avi } \\
\text { (mi) }\end{array}$ & $\begin{array}{c}A_{41} \\
\text { (nud) }\end{array}$ & $\begin{array}{c}\text { A } 4 \text { is } \\
\text { (ruil) }\end{array}$ & \\
\hline 1.4 & 1.2 & $1 . . \hat{i}$ & 2.5 .9 & $4,3.1 \mathrm{n}^{2}$ & $-1.3 .9 .10^{\circ}$ & $2,8.10^{5}$ & $4,1.105$ & $-1,7,10^{5}$ & $-2,2.16^{i}$ & $-7.5 .10^{7}$ & $-1,3 \cdot 11^{5}$ & $2,9.10^{\circ}$ & \\
\hline \multicolumn{14}{|c|}{ 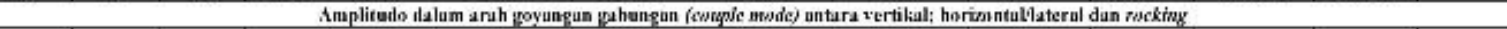 } \\
\hline & & & & $\begin{array}{l}\text { fi. } \\
\text { (mi) }\end{array}$ & $\begin{array}{c}\text { A } \\
\text { (ratl) }\end{array}$ & $\begin{array}{l}\text { Aarisis) } \\
\text { (iii) }\end{array}$ & $\begin{array}{l}\text { Aw...n } \\
\text { (III) }\end{array}$ & $\begin{array}{c}A_{|1| \ldots t} \\
\text { (III) }\end{array}$ & $\begin{array}{c}\text { Awaibl } \\
\text { (iii) }\end{array}$ & & & & \\
\hline & & & & $2.1 .10^{3}$ & $1,7.10^{\circ}$ & $1,10.10^{\circ}$ & $3.2 .20^{\circ}$ & $6,6.10^{\prime \prime}$ & $3,2.10^{\mathrm{n}}$ & & & & \\
\hline
\end{tabular}


3.5 Kontrol terhadap daya dukung statis dan dinamis:

1. Akibat beban statis:

$50 \%$ qall $\geq \mathrm{q}_{\text {(beban luar statis) }} \rightarrow 4,1 \mathrm{~kg} / \mathrm{cm}^{2} \geq 0,20 \mathrm{~kg} / \mathrm{cm}^{2}$ $\rightarrow$ "Aman".

2. Beban statis dan dinamis:

$75 \%$ qall $\geq \mathrm{q}_{\text {(beban statis }+ \text { dinamis) }} \rightarrow 6,2 \mathrm{~kg} / \mathrm{cm}^{2} \geq 0,20$ $\mathrm{kg} / \mathrm{cm}^{2} \rightarrow$ "Aman."

3.6 Perencanaan karet peredam (damping rubber) Data hasil diperlihatkan dalam Tabel 14.

Tabel 14. Desain dan analisis karet/pegas peredam

\begin{tabular}{|c|c|c|c|}
\hline \multicolumn{5}{|c|}{ Dalam arah gerakan vertikal } \\
\hline $\begin{array}{c}\mathbf{k}_{\mathbf{z t}} \\
(\mathbf{k g} / \mathbf{c m})\end{array}$ & $\begin{array}{c}\mathbf{f}_{\mathbf{d z t}} \\
(\mathbf{r p m})\end{array}$ & $\begin{array}{c}\mathbf{T}_{\mathbf{r}} \\
(\mathbf{\%})\end{array}$ & $\begin{array}{c}\mathbf{W}_{\text {din }} \\
(\mathbf{k g})\end{array}$ \\
\hline $\mathbf{1}$ & $\mathbf{2}$ & $\mathbf{3}$ & $\mathbf{4}$ \\
\hline 1287 & 203 & 2 & 4,2 \\
\hline \multicolumn{4}{|c|}{ Dalam arah gerakan horizontal } \\
\hline 183 & 76 & 0,3 & 0,5 \\
\hline
\end{tabular}

3.7 Desain getaran tunggal dengan vibration isolator Data hasil diperlihatkan dalam Tabel 15.

\section{Kesimpulan}

1. Dalam arah gerak vertikal dapat disimpulkan beberapa hal, yaitu: besar redaman mencapai nilai lebih besar 0,70 yang artinya tidak ada getaran atau overdamped, maka bisa dipastikan pondasi tidak mengalami resonansi. Nilai D yang terlalu besar, maka akan terjadi galat matematika, maka diambil nilai D sebesar 0,70 untuk mendapatkan nilai frekuensi resonansi.

2. Dalam arah goyangan rocking dengan vibration isolator, Perbandingan antara frekuensi operasi mesin dengan frekuensi resonansi rocking sebesar 6,9 lebih kecil dari minimal yang disarankan yaitu minimal lebih besar atau lebih kecil $20 \%$ dari frekuensi tersalur.

3. Dari seluruh analisis dan desain, maka diperoleh: Tinggi $=0,7 \mathrm{~m}$; lebar $=1,7 \mathrm{~m}$; panjang $=3,7 \mathrm{~m}$; Kontrol terhadap daya dukung statis dan dinamis dinyatakan "aman”, diperlihatkan Gambar 15.

Tabel 15. Data hasil perhitungan dinamis dalam arah gerak vertikal; horizontal; arah goyangan rocking dengan vibration isolator

\begin{tabular}{|c|c|c|c|c|c|c|c|c|c|c|c|c|c|}
\hline \multicolumn{14}{|c|}{ Dalau aral gerakial rertikal deazan vibswion issofirtior } \\
\hline $\begin{array}{l}r_{x} \\
\text { (ii) }\end{array}$ & $\begin{array}{c}\eta_{c} \\
(\mathrm{rpm})\end{array}$ & $\begin{array}{c}k_{x} \\
(k g j-m)\end{array}$ & $B_{x}$ & $\alpha_{i}$ & $\mathrm{D}_{\mathrm{x}}$ & Dnul & $\begin{array}{c}f_{\mathbf{x}} \\
\left(H_{2}\right)\end{array}$ & $\begin{array}{c}f_{r} \\
\left.\mid H_{i}\right)\end{array}$ & f & $\begin{array}{c}\omega_{N} \\
\text { (rudilut) }\end{array}$ & $\mathrm{r}$ & $\begin{array}{c}\mathbf{F}_{\mathbf{E}} \\
(\mathrm{k})\end{array}$ & $\begin{array}{c}A \\
\text { (iii) }\end{array}$ \\
\hline 1 & 2 & 3 & 4 & 5 & 6 & 7 & s & 9 & 10 & II & 12 & 13 & 14 \\
\hline 1,1 & 1.1 & $1,4.10^{7}$ & 0,3 & 1.4 & 1,1 & 1.1 & 31,5 & 4,5 & 11,2 & 197,6 & I.S & 211 & $5.2 .1 \mathrm{~m}^{\mathrm{m}}$ \\
\hline \multicolumn{14}{|c|}{ Dalam arah gerakian horizontal ilengan wibrutien jsalaraor } \\
\hline $\begin{array}{l}r_{x} \\
\text { (im) }\end{array}$ & $\begin{array}{c}\eta_{x} \\
\text { |rpmi }\end{array}$ & $\begin{array}{c}\mathbf{k} x \\
\left(k_{i} \dot{t} ; m\right)\end{array}$ & $\mathrm{B}_{2}$ & 12. & D. & Dusal & $\begin{array}{c}f_{\ldots .} \\
\left(H_{j}\right)\end{array}$ & $\begin{array}{c}\mathbf{I} \\
\left(\mathbf{H}_{s}\right)\end{array}$ & $r$ & $\begin{array}{c}e_{n} \\
\text { (radidet) }\end{array}$ & $r$ & $\begin{array}{l}\text { F. } \\
\text { (kg) }\end{array}$ & $\begin{array}{c}A \\
(m)\end{array}$ \\
\hline 1,4 & 1.4 & $2,4.10$ & $D, A$ & $2 n$ & 0,4 & 0,9 & 25,6 & 7,6 & 13,4 & 161,1 & $\$ 1,9$ & 211 & $10.10^{8}$ \\
\hline \multicolumn{14}{|c|}{ Dalam arah goyangan rocking dengan vibrrofien isolitios } \\
\hline (mi) & $\underset{(\mathrm{rpm})}{\eta_{6}}$ & ${ }_{(h) / a b\}}^{14}$ & $\mathrm{~B}_{4}$ & $a_{4}$ & $D_{4}$ & Dinal & $\begin{array}{l}f_{r \rightarrow 4} \\
\left(H_{i}\right)\end{array}$ & (1) & $f$ & $\begin{array}{c}\text { En: } \\
\text { (radillet) }\end{array}$ & $r$ & $\begin{array}{c}\text { M1: } \\
\text { (knemi) }\end{array}$ & $\begin{array}{c}A_{2} \\
(\mathrm{~m})\end{array}$ \\
\hline 1,2 & 1.4 & $4,7.10^{\circ}$ & 0.02 & 1,2 & 0,9 & 0.9 & 51,1 & 7,2 & 49 & 205,1 & 0.8 & 0.3 & $4.8 .10^{\prime \prime}$ \\
\hline \multicolumn{14}{|c|}{ 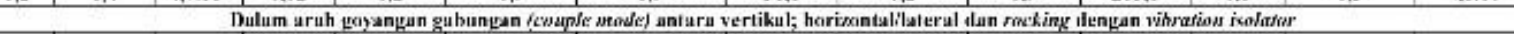 } \\
\hline $\begin{array}{l}\mathrm{r}_{\mathrm{x}} \\
\text { (ai) }\end{array}$ & $\begin{array}{l}r_{\phi} \\
(m)\end{array}$ & $\begin{array}{l}r \Leftrightarrow \\
(\mathrm{m})\end{array}$ & $\begin{array}{c}\text { kx } \\
\text { (kejim) }\end{array}$ & $\underset{\text { (kgim) }}{\text { lot }}$ & $\begin{array}{c}\text { lud } \\
\text { (kL-m.det) }\end{array}$ & $\underset{\text { (kg.m.llet) }}{c_{4}}$ & $\begin{array}{c}c_{\mathrm{a}} \\
(\mathrm{kgg}, \mathrm{det})\end{array}$ & $\begin{array}{c}\text { Lit } \\
\text { (Isididet) }\end{array}$ & $\begin{array}{l}A_{21} \\
(18)\end{array}$ & $\begin{array}{l}\boldsymbol{A}_{\mathrm{a}} \\
\text { (bi) }\end{array}$ & $\begin{array}{c}\text { 4hi } \\
\text { (ruif) }\end{array}$ & $\begin{array}{c}A_{i t} \\
\text { (rail) }\end{array}$ & \\
\hline 1,4 & 1.2 & 1,7 & $2,4,10$ ? & $4.7 .10^{\top}$ & $-1,7.10^{7}$ & $2, x .10^{3}$ & $4.1 .10^{5}$ & $1,7.10^{5}$ & 4, S. $1:^{3}$ & $-1.7 .10^{8}$ & $3,0,10^{8}$ & $2.2 .111^{1}$ & \\
\hline \multicolumn{14}{|c|}{ 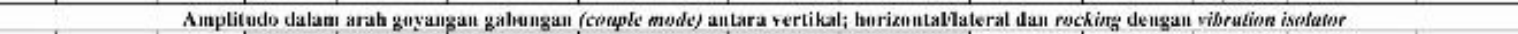 } \\
\hline & & & $\begin{array}{c}\text { A. } \\
\text { (m) }\end{array}$ & $\begin{array}{c}\text { At } \\
\text { (rad) }\end{array}$ & $\begin{array}{l}\text { A.t.ots } \\
\text { (m) }\end{array}$ & $\begin{array}{l}\text { A:wit: } \\
\text { (m) }\end{array}$ & $\begin{array}{c}A \\
(m)\end{array}$ & $\begin{array}{l}\text { A twitusti } \\
\text { (mi) }\end{array}$ & & & & & \\
\hline & & & $5,210^{5}$ & $3,74.10^{*}$ & $7,1.10^{5}$ & $7,2,11^{2}$ & $2,7,10^{*}$ & $5,210^{-5}$ & & & & & \\
\hline
\end{tabular}

3.8 Desain penulangan pondasi dangkal untuk Genset

Desain tulangan menggunakan standar [25]. Berdasarkan [25] dapat diuraikan sebagai berikut:

1. Data-data untuk struktur beton bertulang;

Kuat tekan beton $=30 \mathrm{Mpa}$; kuat leleh baja $=400$ Mpa; berat volume $(\gamma)$ beton bertulang $=2400 \mathrm{~kg} / \mathrm{m}^{3}$; panjang $=3.5 \mathrm{~m}$; tinggi : $0.6 \mathrm{~m}$; lebar : $1.5 \mathrm{~m}$; berat pondasi $=7560 \mathrm{~kg}$; berat mesin $=2075 \mathrm{~kg}$; beban dinamis $=4,22 \mathrm{~kg}$; tulangan pokok = D 20 .

2. Hasil perhitungan desain:

Analisis dan desain penulangan untuk pondasi diperlihatkan dalam Tabel 16 berdasarkan SNI 17262012 [25].

Tabel 16. Desain penulangan pondasi dangkal

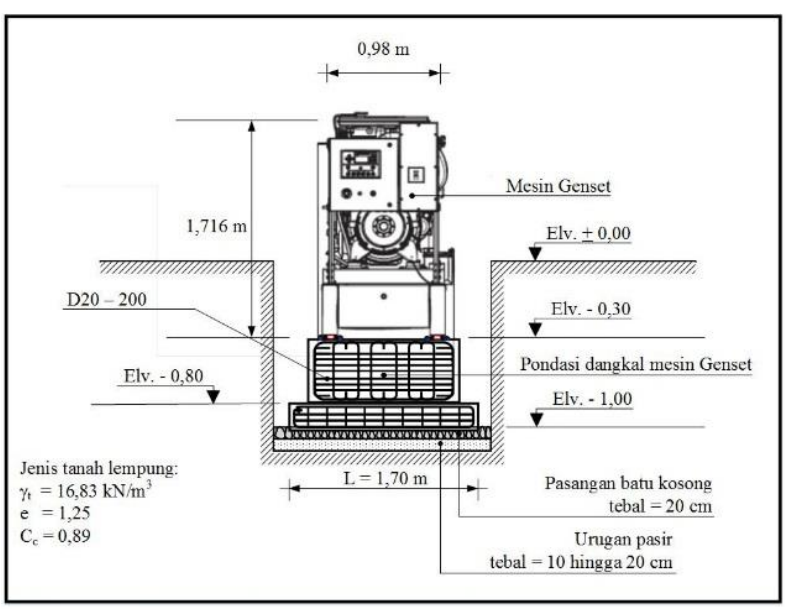

\begin{tabular}{|c|c|c|c|c|c|c|c|}
\hline \multicolumn{3}{|c|}{ Analisis pembebanan } & \multicolumn{5}{|c|}{ Analisis penulangan } \\
\hline$\underset{(m \mathrm{~m})}{\mathrm{d}}$ & $\underset{(\mathrm{kg} / \mathrm{m})}{\mathrm{q}}$ & $\begin{array}{c}\mathbf{M}_{\text {maks }} \\
(\mathrm{Nmm})\end{array}$ & $\begin{array}{c}\mathbf{J}_{\mathrm{d}} \\
(\mathrm{mm})\end{array}$ & $\begin{array}{l}A_{\text {Aperlov) }} \\
\left(\mathrm{mm}^{2}\right)\end{array}$ & $\rho_{\min }$ & $\begin{array}{c}\text { Jarak tulangan } \\
\text { pokok }(\mathrm{mm})\end{array}$ & $\begin{array}{c}\text { Diambil tulangan } \\
\text { pokok }\end{array}$ \\
\hline 1 & 2 & 3 & 4 & 5 & 6 & 7 & 8 \\
\hline 515 & 2754 & $24,1,10^{6}$ & 437,8 & 171 & 0,0035 & 1837 & D20-200 \\
\hline
\end{tabular}

Gambar 15. Hasil analisis dan perencanaan pondasi genset 
4. Kontrol perhitungan karet peredam vibration [16]Richart, F. E. 1962. Foundation vibrations. Trans. ASCE, isolator. Dari hasil perhitungan didapatkan spesifikasi karet peredam Karman K3-C51 dapat meredam getaran yang terjadi diperlihatkan dalam Gambar 16.

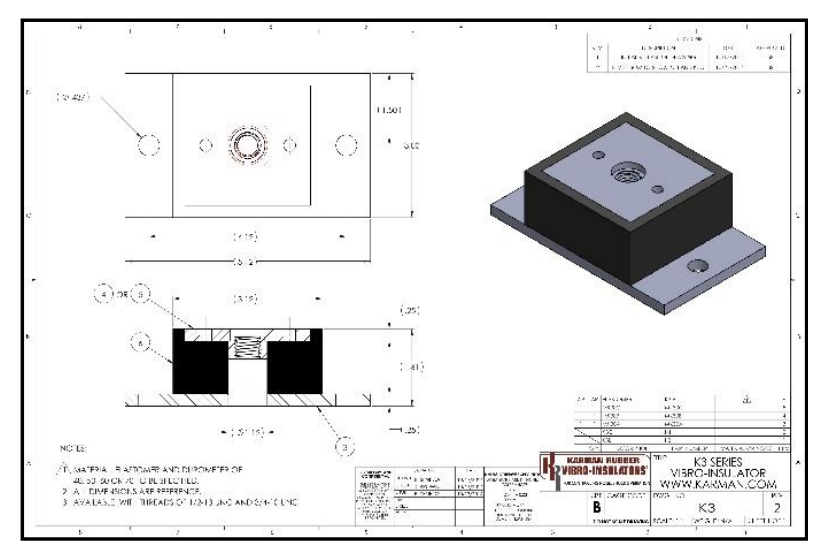

Gambar 16. Hasil desain dan perencanaan karet/pegas peredam [14]

5. Kontrol terhadap penurunan tanah akibat pondasi: Penurunan yang terjadi masih dalam batas-batas yang diijinkan.

\section{Daftar Rujukan}

[1] Anastasopoulos I, Kontoroupi T. 2014. Simplified approximate method for analysis of rocking systems accounting for soil inelasticity and foundation uplifting. Soil Dyn Earthq Eng 2014;56:28-43.

[2] Blake, M.P. 1964. New Vibration Standards for Maintenance. Hydrocarbon Processing Petroleum Refiner, Vol.43, No.1, pp 111-114.

[3] Baxter, R.L., Bernhard, D.L., 1967. Vibration Tolerances for Industry, in: ASME Paper 67-PEM-14, Plant Engineering and MaintenanceEngineer. Detroit, Michigan.

[4] Beredugo, Y.O. and Novak, M. 1972. Coupled horizontal and rocking vibration of embedded footings. Canadian Geotechnical Journal, 9(4): pp. 477-497.

[5] Braja, M.D. 2011, "Principles of Foundation Engineering, SI", $7^{\text {th }}$ edition, Global Engineering: Christopher M. Shortt.

[6] Bowles, J.E. 1977. Foundation Analysis and Design. The McGraw-Hill Companies, Inc. International Edition.

[7] El Ganainy, H, El Naggar M.H. 2009. Efficient 3D nonlinear Winkler model for shallow foundations. Soil Dyn Earthq Eng 2009;29:123648.http://dx.doi.org/10.1016/j.soildyn.2009.02.002.

[8] Febrianto. 2011. Perencanaan dan Pelaksanaan Pondasi Mesin Generator PT EPFM [Skripsi]. Makasar: Fakultas Teknik Universitas Hasanuddin.

[9] Hardiyatmo, H., C. 2011. Analisa dan Perancangan Fondasi. Yogyakarta: Gadjah Mada University Press.

[10] Irsyam, M, Sahadewa A, dan Darjanto H. 2008. Dinamika tanah dan Fondasi Mesin. Bandung: ITB.

[11]Janbu, N., Bjerrum, L., and Kjaernsli B. 1956. Veiledning ved losning av fundamenteringsoppgaver. Norwegian Geotechnical Institute, Publication No. 16, 93 p. (in Norwegian).

[12] KepMen Negara KLH. 1996. No.: KEP-49/MENLH/11/1996. Tentang Baku Tingkat Getaran.

[13] Kutter BL, Moore M, Hakhamaneshi M, Champion C. 2016, Rationale for shallow foundation rocking provisions in ASCE 4113. Earthq Spectra 32, pp. :1097119.http://dx.doi.org/10.1193/121914EQS215M.

[14] Karman rubber vibro-insulator. 2018. Karman Rubber Company. 2331 Copley Road Akron, OH 44320. USA

[15] Prakash, S. and Puri, V.K. 1988. Foundation for Machines Analysis and Design. John Wiley \&Sons, New York.
111 , pp. $863-898$.

[17] Rocscience Inc. 2016. RS2-2D finite element program for soil and rock applications.

[18] Robertson, P.K., and Campanella, R.G. 1986a. Interpretation of cone penetration tests - Part I (sand). Canadian Geotechnical Journal, 20(4): 718-733.

[19] Skempton, A.W and Mac Donald, W.H. 1956. Allowable Settlement of Building. Proceeding Institute of Civil Engineers, Part III, Vol. 5, pp. $727-768$.

[20] Robertson, P.K., and Campanella, R.G. 1986b. Interpretation of cone penetration tests - Part II (clay). Canadian Geotechnical Journal, 20(4): 734-745.

[21] Robertson, P.K. 2010. Interpretation of cone penetration tests - a unified approach, Canadian Geotech. J., 46(11):1337-1355.

[22] Sigit, A.S. 1996. Buku Ajar Pondasi Dinamis. Surabaya: ITS.

[23] Schneider, J.A., Randolph, M.F., Mayne, P.W., and Ramsey, N. 2008. Analysis of Factors Influencing Soil Classification Using Normalized Piezocone Tip Resistance and Pore Pressure Parameters. Journal of Geotechnical and Geoenvironmental Engineering, 134(11), pp: 1569-1586.

[24] Schmertmann, J. H. 1978. Guidelines for cone penetration test, performance and design U.S. Department of Transportation, Washington, DC, Report No. FHWA-TS-78209, $145 \mathrm{p}$.

[25] SNI 1726. 2012. Tata cara perencanaan ketahanan gempa untuk struktur bangunan gedung dan non gedung. Badan Standardisasi Nasional. ICS 91.120.25;91.080.01.

[26] Specification of Triton Generating Set. 2018. www.gopwer.com

[27] Wayne, C.T. 1992. Foundation Design. Prentice Hall of India Private Limited, M-97 Connaught Circus, New Delhi-110001.

[28]Zhang J, Tang Y. 2007. Finite element modeling of shallow foundations on nonlinear soil medium. Struct., Los Angeles. 